\title{
Recuperación de Especies Hortícolas Nativas del Trópico Húmedo, Santo Domingo de los Tsáchilas, Ecuador, Diciembre 2008
}

\section{Autores:}

Ing. Xavier López M. Ing. Miriam Recalde Q. Ing. Rodrigo Saquicela R. 


\section{Resumen}

La investigación se realizó en la granja experimental de la UTE campus Santo Domingo, con el objetivo de rescatar especies hortícolas nativas del trópico húmedo ecuatoriano para lo cual se identificó y caracterizó botánicamente las especies encontradas, estableciendo sus ciclo de cultivo y labores culturales, monitoreando el ataque de plagas en estos vegetales; en los recorridos realizados se identificaron 5 especies hortícolas: Namau, Col de monte, Culantro de pozo, sambo y zapallo de monte. En el experimento se estableció un diseño de parcelas divididas, con diferentes repeticiones según la especie, en los cuales se evaluaron dos distanciamientos de siembra y para algunas especies la incidencia de sombra. Se hizo la prueba de significación de Tukey al 5\% para las fuentes de variación significativas o altamente significativas y transformación de raíz cuadrada para el número de hojas. Para el cilantro no hay diferencias significativas en la producción de hojas con las distintas distancias de siembra. Para la col del monte, sembrada por semilla, al sufrir un ataque de cochinillas no se pudo evaluar confiablemente el efecto de la sombra y distancia de siembra en la producción de hojas. Para las coles de monte sembradas por estacas, sufrieron el ataque de cochinillas, pero al tener reservas nutritivas en la estaca, pudo crecer más que la sembrada por semillas. En general las plantas sembradas por estacas y bajo sombra se desarrollaron mejor. El Namau es susceptible al ataque de nemátodos por lo que no se pudo evaluar la producción de tubérculos. El sambo es susceptible a la competencia por malezas y el zapallo nunca creció lo suficiente como para transplantarlo al terreno definitivo.

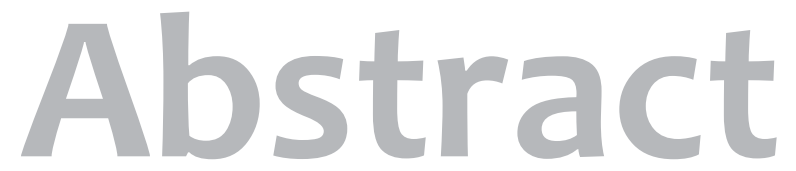

The research was conducted at the experimental farm of the campus UTE Santo Domingo, with the objetive of rescuing native horticultural species of the humid tropics of Ecuador. This was botanically identified and characterized the species found by setting their cycles of cultivation and mantaining work, monitoring the pest attack in these plants. In the visits five vegetable species were identified: Namau, bush cabbage, cilantro or pond well, sambo and mountain pumpkin. The experiment was a split plot design with observations over time, with different repetitions depending on the species, in which were evaluated two different distances of planting and for some species the impact of shade. For the cilantro no significant differences in the production of leaves with different distances of planting. Col for the bush, planted seed, to suffer an attack of insects it was unable to assess reliability the effect of shade and planting distance in the production of leaves. For bush cabbages planted by cuttings, attacked by insects, but having nutritive stake reservations, could grow by more than the seed sown. The Sambo proved to be very susceptible to competition with weeds and the pumpkin did not grow with vitality for transplantation. 


\section{Introducción}

Se trata de dar un lugar en el campo hortícola a especies vegetales que se encuentran en la zona y que han servido como hortalizas en la alimentación de los habitantes nativos del sector no siendo conocidas por la horticultura tradicional y desplazada por hortalizas que se cultivan en otras latitudes.

El problema nace desde la época de la conquista española pues nos impusieron costumbres, tradiciones, religiones y también especies y sistemas de cultivo relegando a último lugar los propios de nuestro sector establecidos en un sistema agro climático nativo que no necesitan ser introducidos, para luego de varios años redescubrirlos y lastimosamente es gente extranjera la que encuentra ventajas y valores alimenticios o medicinales y las patentan o lanzan a los mercados como ocurrió con el babaco frutal nativo andino lanzado al comercio mundial por Nueva Zelanda.(4)

El estado actual de este campo en nuestro país existe poco o casi nada en estudios sobre este tipo de hortalizas, la información empírica se la puede obtener de los nativos de las regiones tropicales húmedas que son los que consumen y conocen sus propiedades con la dificultad que al perder ellos su identidad cultural también están perdiendo sus cultivos nativos. (4)

En otros países tropicales como el caso de Costa Rica han aprovechado al máximo todo este tipo de recursos, siendo en este el culantro coyote Eringyum foetidum L. un cultivo para exportación que es el mismo de nuestro sector el culantro de pozo (2)

Con estas nuevas tendencias de apertura de mercados globalizados estas especies hortícolas son una alternativa, oportunidad para nuestros pequeños agricultores de poder enfrentar la crisis generando fuentes de trabajo, mejorando la producción de alimentos para una creciente población. (2)

Todas estas hortalizas siendo autóctonas de estas zonas se las encuentra de forma silvestre en diferentes ecosistemas de las regiones tropicales húmedas, su cultivo conlleva una serie de técnicas y conocimientos, climas y suelos particulares para lo cual se necesitará no solo una sino varias investigaciones para poder afianzar su producción comercial. $(2,4)$

\section{Objetivos}

\section{Objetivo General}

Rescatar especies hortícolas nativas del trópico húmedo ecuatoriano Objetivos Específicos

- Identificar y caracterizar botánicamente las especies hortícolas nativas de la zona que han sido relegadas por los colonizadores.

- Establecer ciclos de cultivo de las especies hortícolas identificadas.

- Definir las labores preculturales y culturales para el cultivo. 
- Monitorear la presencia de plagas y enfermedades.

- Documentar y divulgar la información obtenida

\section{Materiales, Métodos y Procedimientos}

\section{Materiales}

- Material experimental

Especies hortícolas nativas encontradas

- Material de campo

Herramientas manuales

GPS

Cámara fotográfica

- Material de oficina

Computadora

\section{Método}

La presente investigación se desarrollo en la granja experimental de la Universidad Tecnológica Equinoccial, ubicada en Santo Domingo-Ecuador a $600 \mathrm{msnm}$, con una temperatura media anual de $24,5^{\circ} \mathrm{C}$ y una precipitación de $2800 \mathrm{~mm} / \mathrm{año}$, la zona se clasifica como Bosque Húmedo Tropical (5). En este trabajo se involucraron investigaciones descriptivas, cualitativas y experimentales. De acuerdo a los objetivos planteados se identificaron las especies mediante visitas y entrevistas a agricultores nativos y colonos del cantón Santo Domingo de los Colorados como punto representativo del área de investigación, avanzando a lugares que presenten este tipo de climas se estableció contacto con las comunidades Shuar, donde trabajos similares nos permitieron describir las plantas hortícolas nativas. Se caracterizó y clasificó los órganos vegetales que componen estas especies bajo los formatos ya establecidos $(3,6)$. Con un diseño de parcelas divididas manejando diferentes repeticiones de acuerdo a la cantidad de material vegetal por especie de cultivo, se pudo establecer labores culturales necesarias de acuerdo a las especies en investigación; así como ciclos del cultivo y presencia de plagas y enfermedades.

Según el tipo de hortaliza cultivada, se evalúo: distanciamientos de siembra, intensidad de luz, incidencia de plagas y enfermedades, peso de materia fresca y seca, complementando con un análisis bromatológico

\section{Manejo del Experimento}

El presente estudio constó de dos etapas, la primera nos ayudó a encontrar las especies hortícolas para lo cual se realizó visitas a diferentes comunidades, unas nativas como los de las etnias Tsáchilas y otras en asentamientos colonos en el sector como San Bernabé, Ecuador, Jesús del Gran Poder, Tinalandia, Congomita y Congoma, en las cuales se conversó con los agricultores los cuales nos ayudaron a identificar las especies de hortalizas nativas de consumo; además se pudo establecer contacto con el CARE institución que se encontraba desarrollando el proyecto titulado "RESCATE DE CONOCIMIENTOS AGRICOLAS ANCESTRALES AJA- SHUAR” en las comunidades Shuar del cantón Macas Provincia de Morona Santiago en la cual pudimos conversar con los nativos de la zona e identificar especies nativas de esta región de características climáticas similares a las de nuestra 
localidad. Una vez identificadas las especies y con la recolección de semillas y órganos vegetales para su multiplicación, se realizó la segunda fase del trabajo que consistió en el estudio de caracterización botánica de acuerdo a los estándares de clasificación de órganos vegetales (3), para el estudio de ciclo de cultivo, labores culturales e incidencia de plagas se realizó un cultivo experimental en campo estudiando dos distanciamientos de siembra para las especies (1).

\section{Resultados y Discusión}

\section{Ubicación y caracterización botánica de}

\section{las especies hortícolas}

\section{Culantro de pozo Eringyum foetidum L.}

Ubicación geográfica de recolección

\begin{tabular}{|l|l|l|}
\hline \multicolumn{1}{|c|}{ Coordenadas } & \multicolumn{1}{c|}{ Altura msnm } & Lugar \\
\hline $00^{\circ} 14^{\prime} 41^{\prime \prime} \mathrm{S}$ & 540 & San Bernabé \\
\hline $79^{\circ} 10^{\prime} 19^{\prime \prime} \mathrm{O}$ & & \\
\hline
\end{tabular}

Ubicación taxonómica.

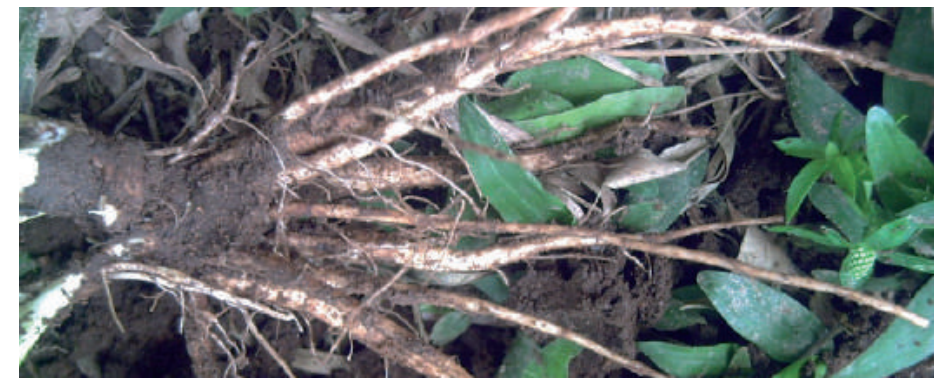

Raíz.- Por su origen es una raíz normal proviene de la ridícula del embrión teniendo una forma fasciculada de consistencia semileñosas todo sus ciclo lo desarrolla bajo la tierra, con un ciclo de vida anual.

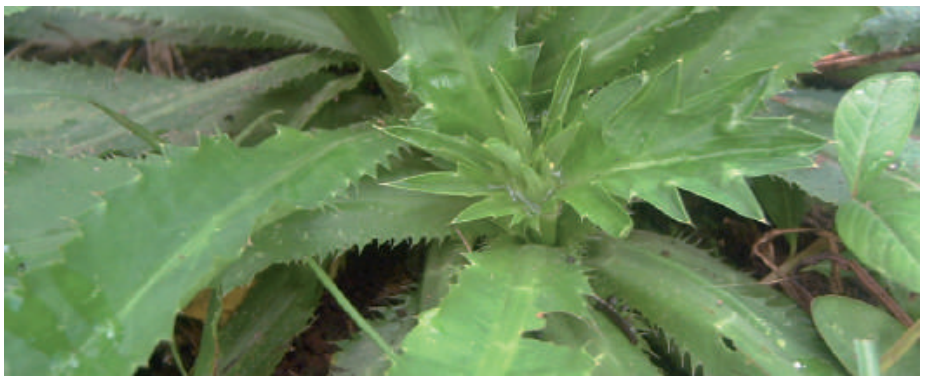

Tallo.- Éste es de consistencia carnosa, discal macizo de forma cilíndrica, crecimiento erguido con ramificación monopódica, aclarando que emite un tallo floral en el centro de la roseta y este alcanza una altura de 30 a $50 \mathrm{~cm}$ de alto.

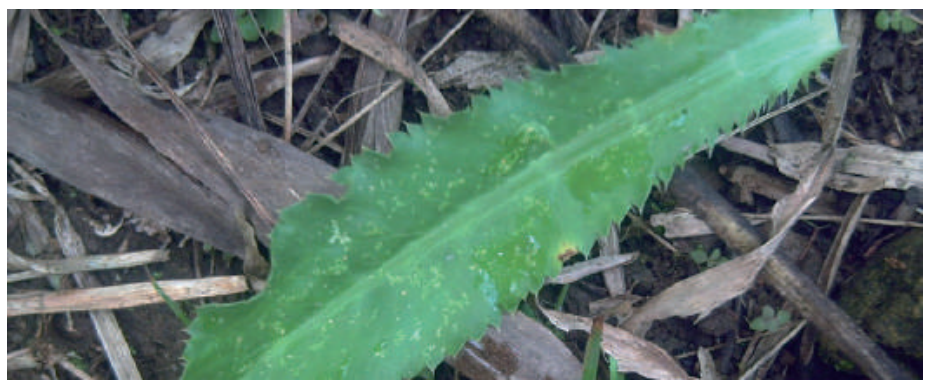

Hojas.- Las hojas son de forma alargada, paralelinervadas, planas con un borde aserrado de color verde claro a obscuro. 


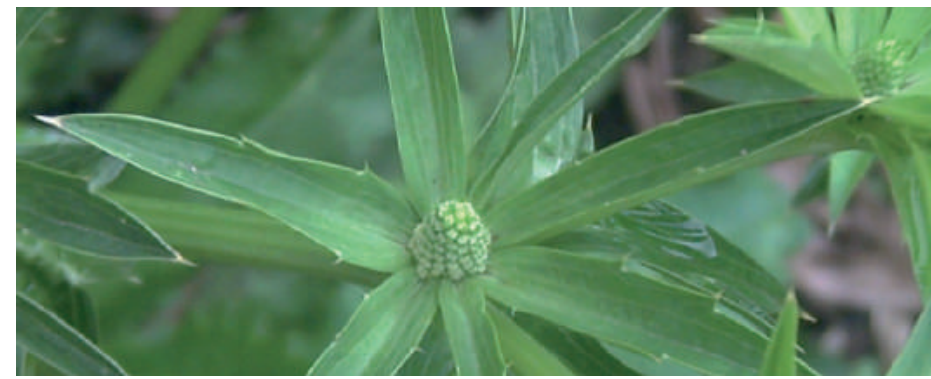

Flores.- Posee una inflorescencia en antela de espiga y cada flor es monoica hermafrodita.

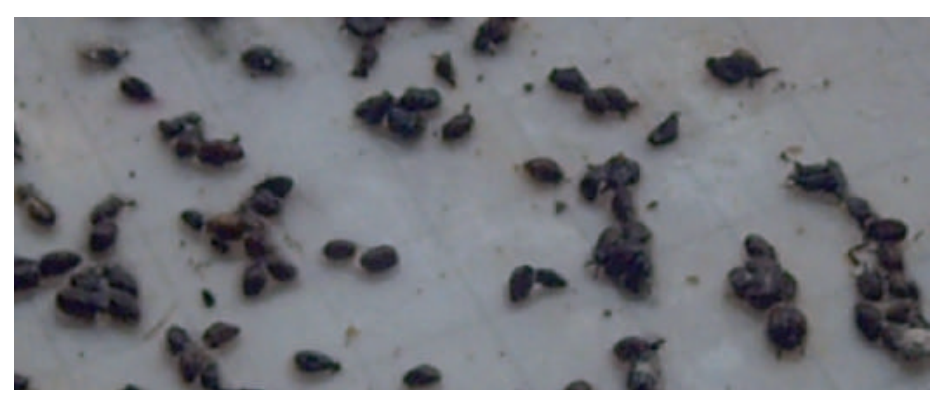

Frutos y semillas.- Tiene frutos secos dehiscentes manteniendo a la semilla que es un folículo en una cápsula.

\section{Zapallo de montaña Cucúrbita Ssp}

Ubicación geográfica de recolección

\begin{tabular}{|l|l|l|}
\hline Coordenadas & Altura msnm & Lugar \\
\hline $00^{\circ} 17^{\prime} 31^{\prime \prime} \mathrm{S}$ & 560 & Tinalandia \\
\hline $79^{\circ} 03^{\prime} 07^{\prime \prime} \mathrm{O}$ & & \\
\hline
\end{tabular}

Ubicación taxonómica

Familia: Cucurbitáceas

Genero: Cucurbita

Especie: Spp

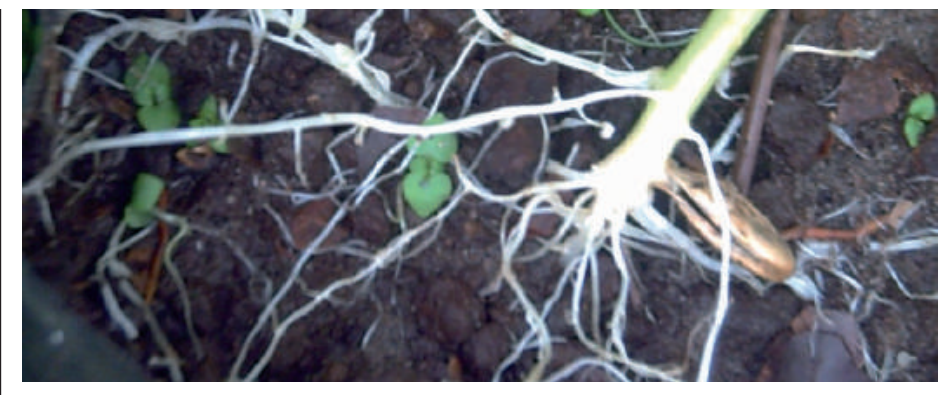

Raíz.- Posee una raíz de origen normal de forma pivotante bien identificada su raíz principal y las raíces secundarias con abundantes pelos absorbentes, de contextura fibrosa, las características del tallo le permite tener raíces adventicias.

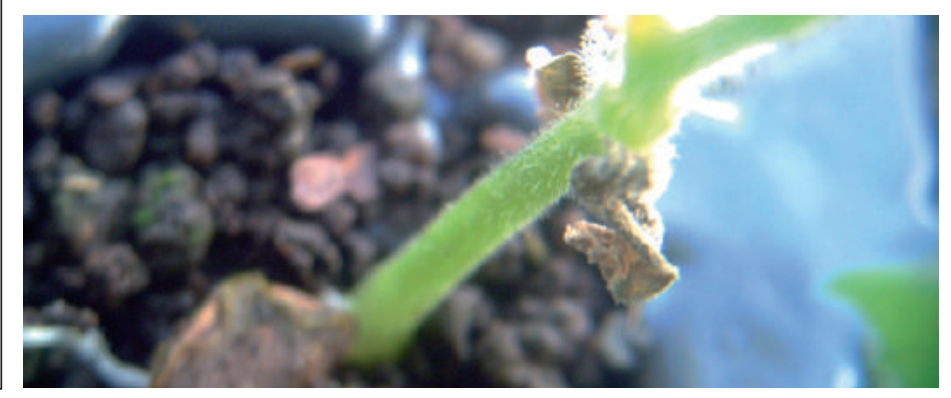

Tallo.- Esta familia de vegetales se caracteriza por tener tallos trepadores de consistencia herbácea, pubescentes, policotomicos.

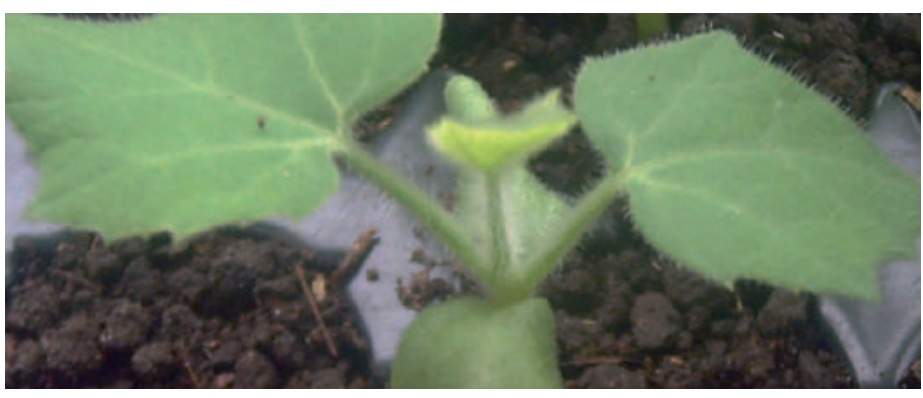

Hojas.- Son simples, acorazonadas, con un borde del limbo entero paralelinervadas. 


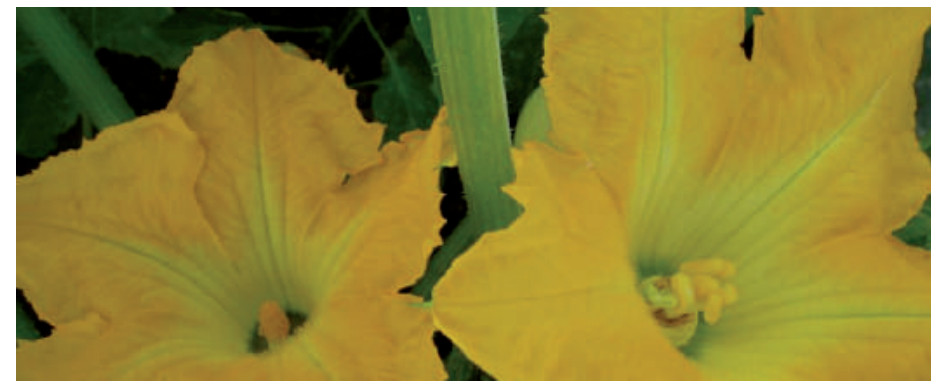

Flores.- Las cucurbitáceas son plantas monoicas es decir poseen flores masculinas y femeninas en el mismo vegetal.

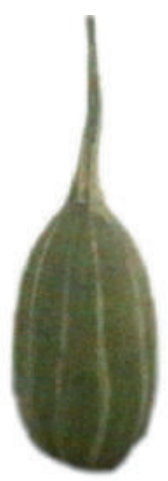

Fruto.- El fruto carnoso está clasificado como un pepónide, el que guarda a semillas indehiscentes

\section{Namau.- Pachyrhyzus tuberosus Spreng}

Ubicación geográfica de recolección

\begin{tabular}{|l|l|l|}
\hline Coordenadas & Altura msnm & Lugar \\
\hline $02^{\circ} 20^{\prime} 27^{\prime \prime} \mathrm{S}$ & 1110 & Comuna Shuar \\
\hline $78^{\circ} 05^{\prime} 29^{\prime \prime} \mathrm{O}$ & & \\
\hline
\end{tabular}

Ubicación taxonómica

Familia: Leguminosas

Género: Pachyrhyzus

Especie: Tuberosus

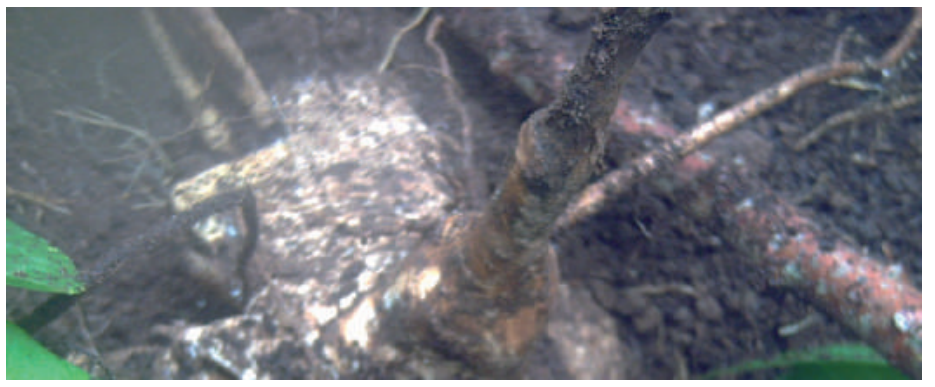

Raíz.- Tienen una raíz pivotante de origen normal de contextura semileñosas volviéndose tuberosa en la etapa de desarrollo de la planta.

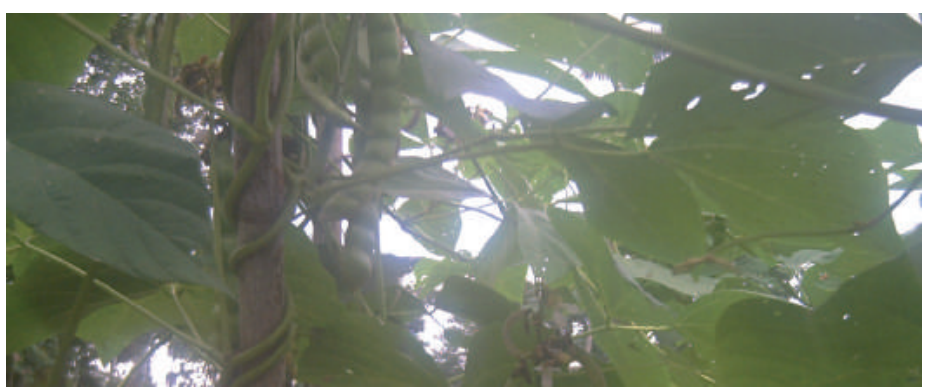

Tallo.- Poseen un tallo trepador cilíndrico de consistencia herbácea

no pubescentes monopodicos.

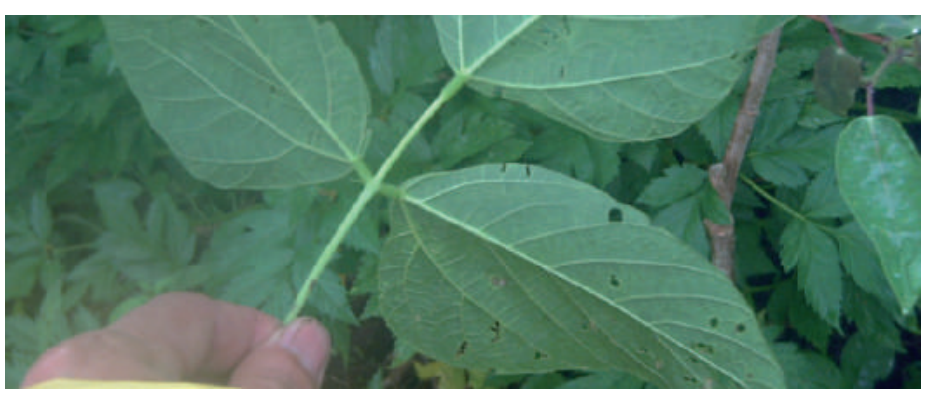

Hojas.- Son compuestas trifoliadas, de forma acorazonada, enteras por su borde y paralelinervias

\section{Tsafiqui=}




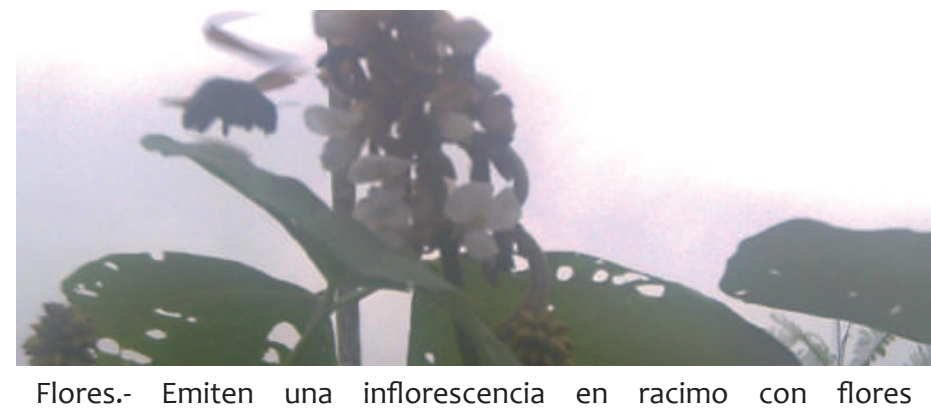

hermafroditas, monoicas.

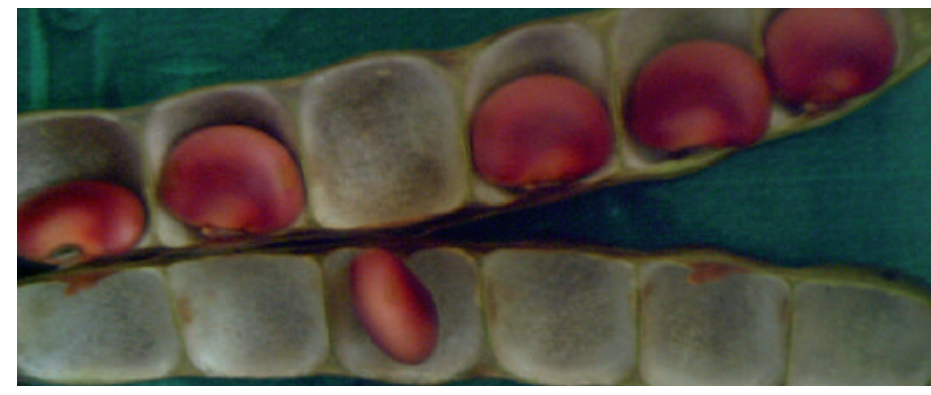

Frutos.- El fruto es de característica seca dehiscente ubicándose en

el tipo de legumbre guardando las semillas dentro de los carpelos.

\section{Col de monte Carica monoica Desf}

Ubicación geográfica de recolección

\begin{tabular}{|l|l|l|}
\hline Coordenadas & Altura msnm & Lugar \\
\hline $00^{\circ} 01^{\prime} 08^{\prime \prime} \mathrm{S}$ & 570 & San Bernabé \\
\hline $79^{\circ} 05^{\prime} 28^{\prime \prime} \mathrm{O}$ & & \\
\hline
\end{tabular}

\section{Ubicación taxonómica}

Familia: Caricáceas

Genero: Carica

Especie: monoica

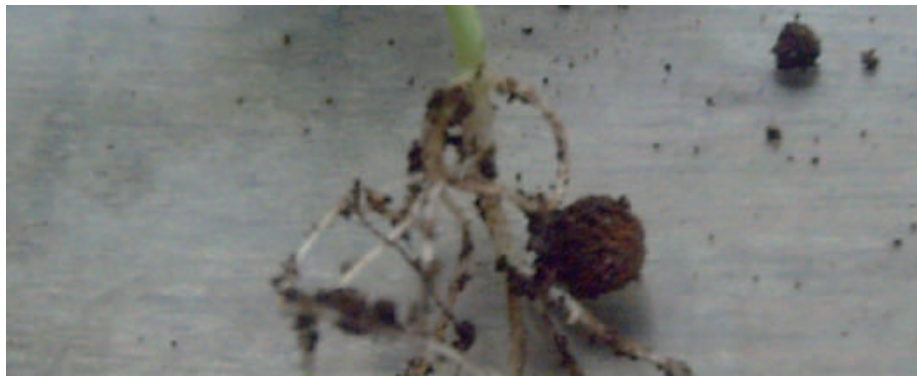

Raíz.- Tiene una raíz normal que proviene de la ridícula del embrión de forma pivotante con raíces secundarias gruesas.

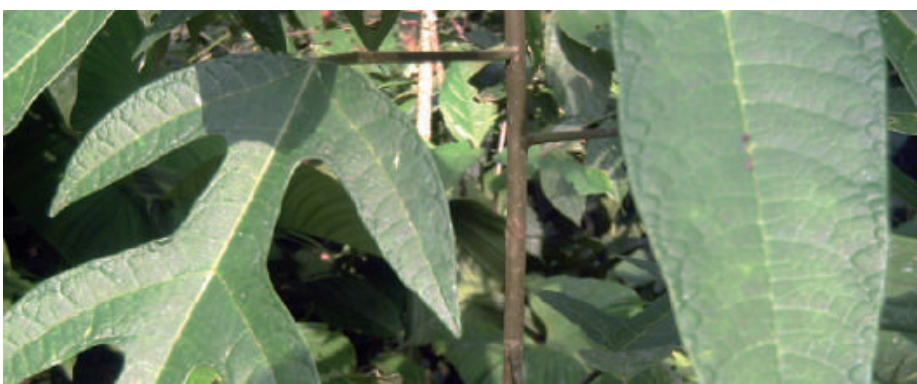

Tallo.- De crecimiento monopódico y consistencia semileñoso herbáceo es cilíndrico y no protubescente.

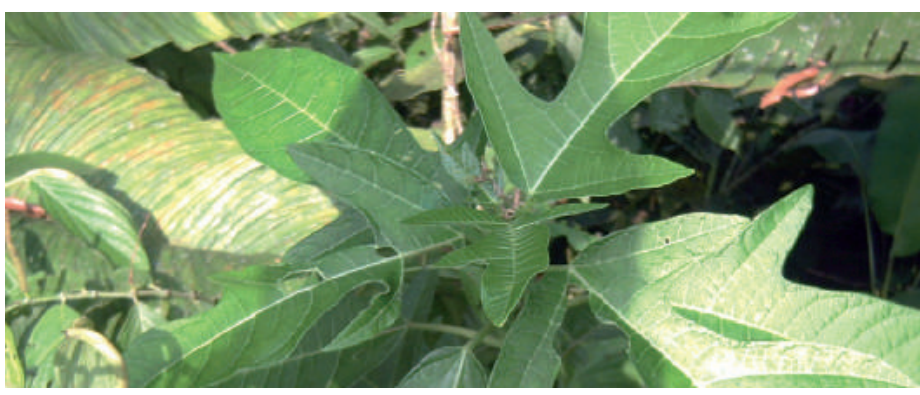

Hojas.- Simples de forma palmada con lóbulos paralelinervias con el filo del borde dentado.

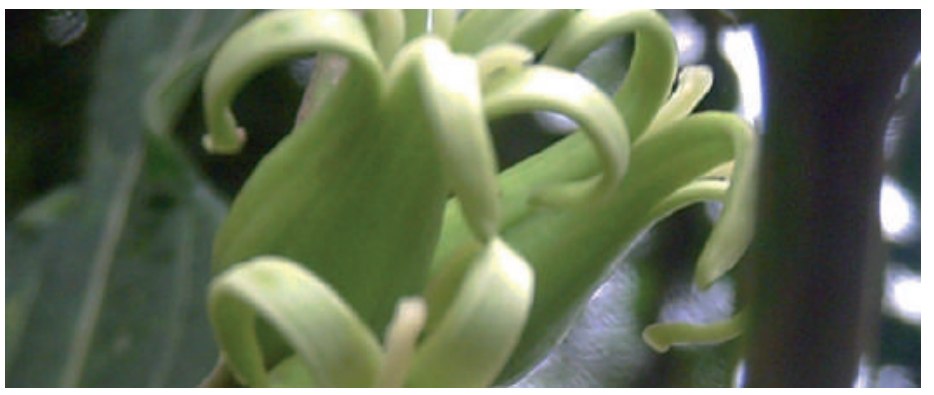

Flores.- Posee flores hermafroditas, pistiladas y estaminadas en una misma planta las mismas que nacen en las axilas de las hojas. 


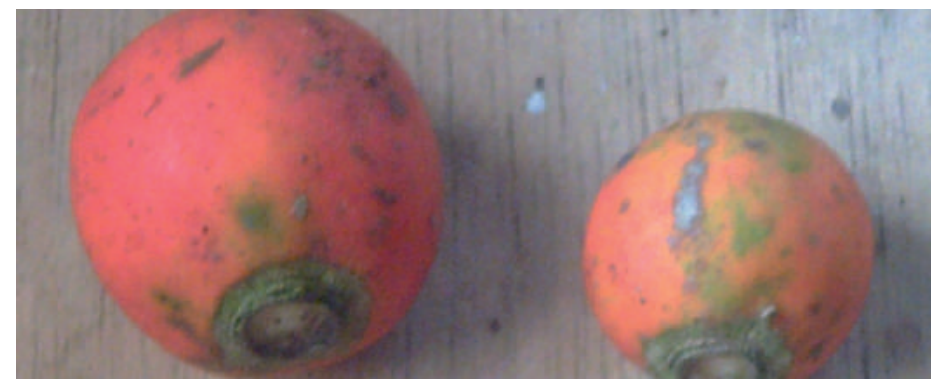

Frutos.- El fruto es carnoso clasificándose dentro de estos como una baya alojando las semillas dentro del pericarpio

\section{Sambo de monte Cucurbita Spp}

Ubicación geográfica de recolección

\begin{tabular}{|l|l|l|}
\hline Coordenadas & Altura msnm & Lugar \\
\hline $0^{\circ} 23^{\prime} 14^{\prime \prime} \mathrm{S}$ & 504 & Cóngoma \\
\hline $79^{\circ} 22^{\prime} 24^{\prime \prime} \mathrm{O}$ & & \\
\hline
\end{tabular}

Ubicación taxonómica

Familia: Cucurbitáceas

Genero: Cucurbita

Especie: Spp

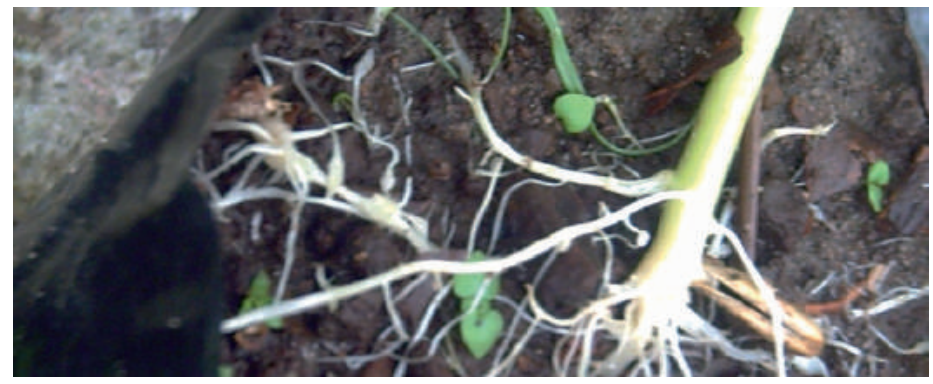

Raíz.- Es de origen normal de forma pivotante posee raíz principal y raíces secundarias con abundantes pelos absorbentes, de consistencia fibrosa.

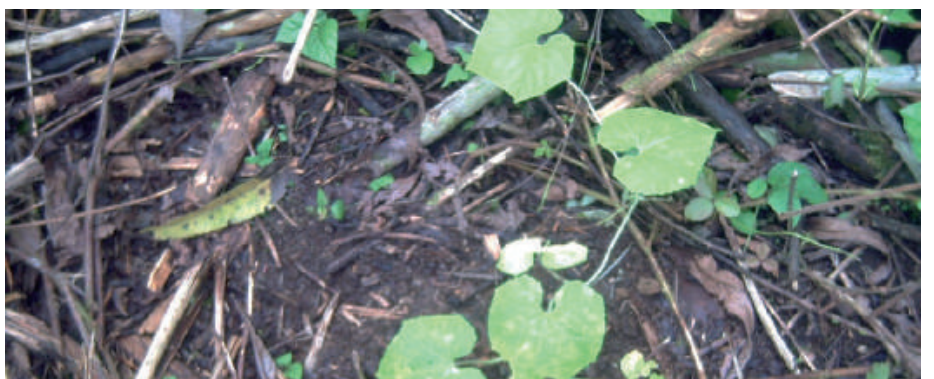

Tallo.- De consistencia herbácea son tallos policotomicos de característica trepadora, pubescentes.

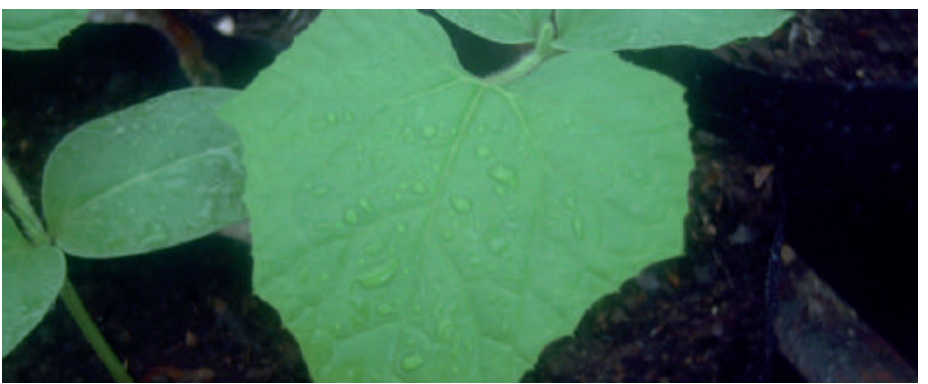

Hojas.- Simples, acorazonadas, con un borde del limbo entero paralelinervadas.

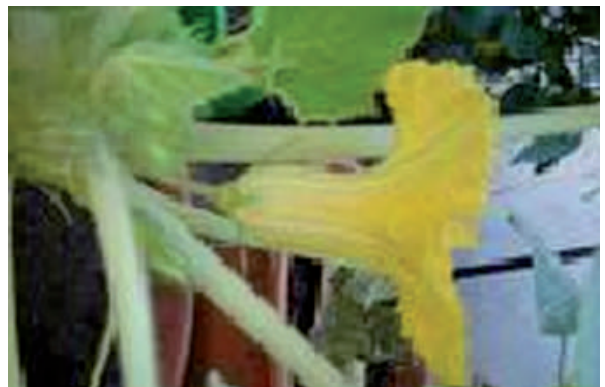

Flores.- Son plantas monoicas es decir poseen flores estaminadas y pistiladas en el mismo vegetal.

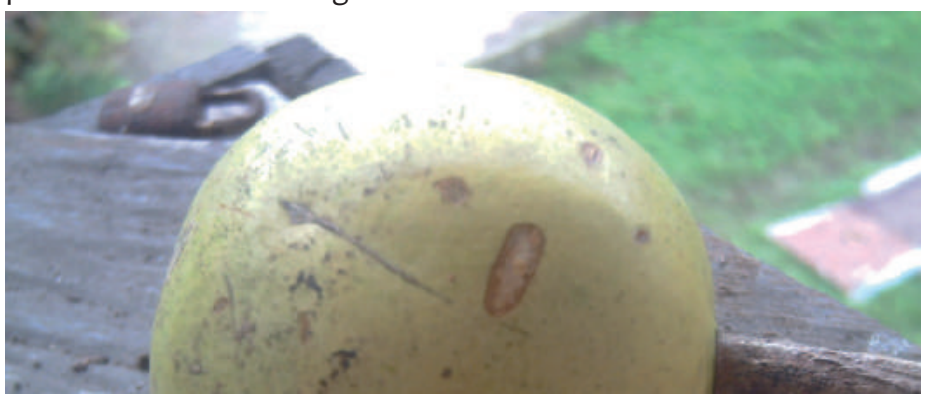

Fruto.- El fruto carnoso está clasificado como un pepónide, el que guarda a semillas indehiscentes.

\section{Tsafiqui=a:}




\section{Ciclos de cultivo fonología y producción}

\section{Cilantro}

Fenología

Figura No 1.

Fenología del cilantro

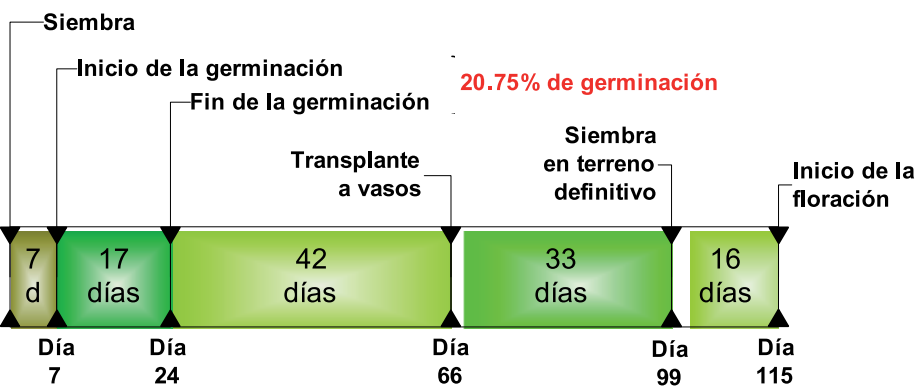

El cilantro tiene $20.75 \%$ de germinación de sus semillas. Al día 115 de la germinación ocurre el inicio de la floración por lo que los nutrientes acumulados serán destinados a las flores (Figura No 1) Cultivo

\section{Figura No 2}

\section{Número de hojas y largo de la hoja más grande del cilantro}

a. Número de hojas, miles/ha

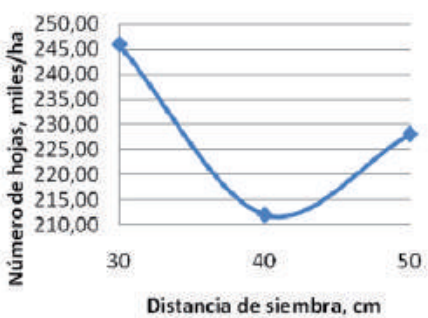

b. Largo de la hoja más grande, $\mathrm{cm}$

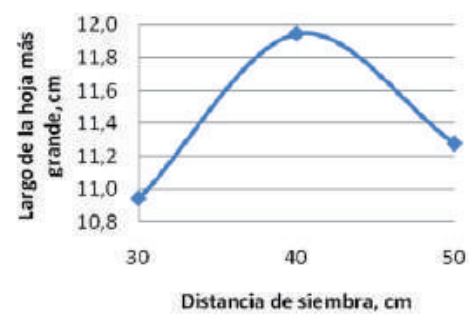

Para las distancias de siembra se observan diferencias no significativas en el número de hojas y hoja más grande del culantro (Anexo 1). No se observa una tendencia clara, que a medida que aumente la distancia de siembra disminuya o aumente el número de hojas y el largo de la hoja más grande (Figura No 2)
Las distancias de siembra, no influye significativamente en el número de hojas ni en el largo de la hoja más grande en el cultivo de cilantro

\section{Análisis bromatológico del cilantro}

\begin{tabular}{|c|c|c|c|c|c|c|}
\hline Identificación & Humedad & Ceniza & Grasa & Proteína & Fibra & ELNN \\
\hline Hojas secas & 0,00 & 22,10 & 7,6 & 14,7 & 5,5 & 50,1 \\
\hline Hojas frescas & 72,6 & 6,06 & 2,08 & 4,01 & 1,51 & 13,74 \\
\hline
\end{tabular}

ELNN Elementos no nitrogenados

\section{Col del monte}

Semilla

Fenología

Figura No 3

Fenología de la col del monte sembrada por semilla

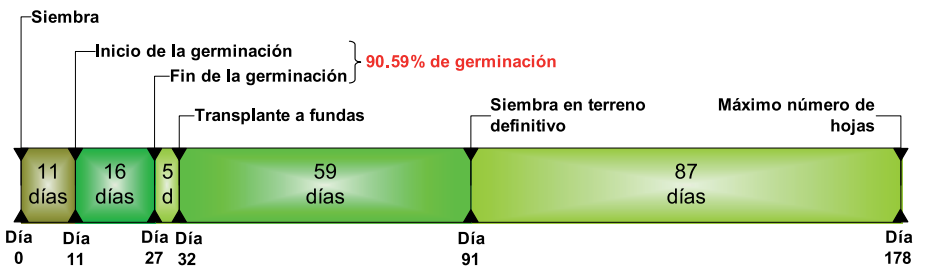

La col del monte sembra da por semilla tiene $90.59 \%$ de germinación, y este periodo demora 16 días. El máximo número de hojas ocurre a los 178 días después de la germinación (Figura No 3)

Cultivo

Altura de la planta

\section{Figura No 4}

Interacciones de sombra, distancia y días después del transplante en la col del monte sembrada por semilla

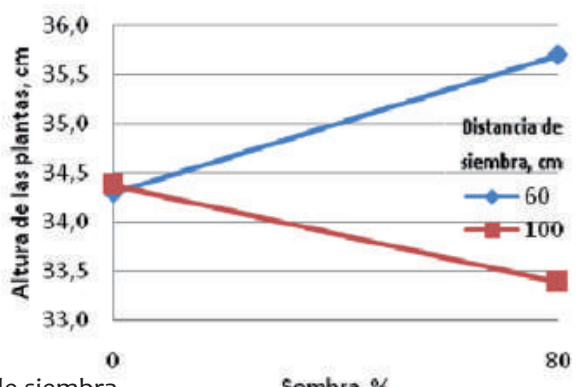

a. Sombra por distancia de siembra Sombra, $\%$ 


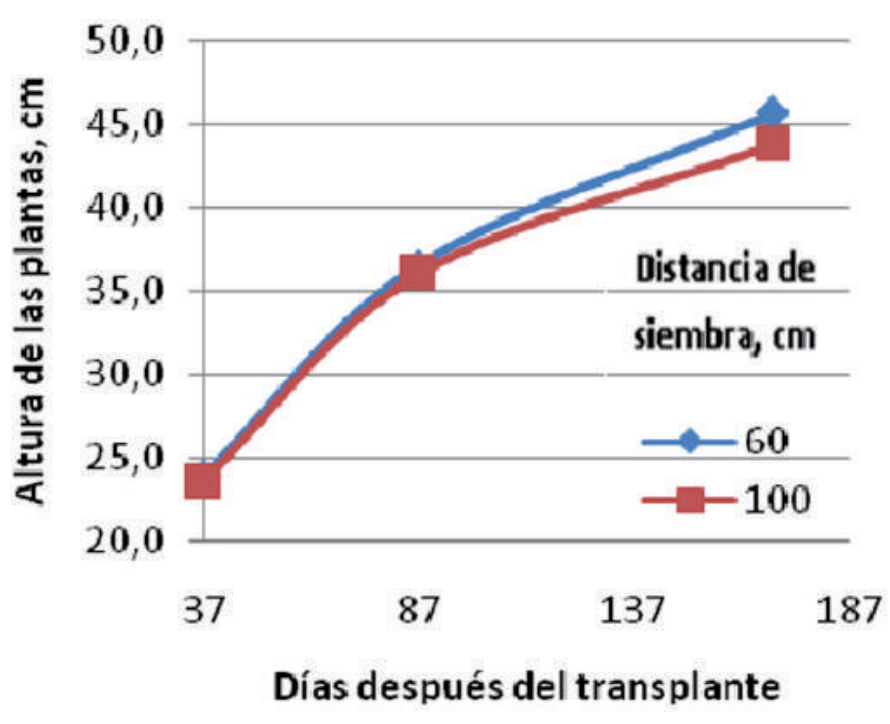

b. Días después del transplante por distancia de siembra

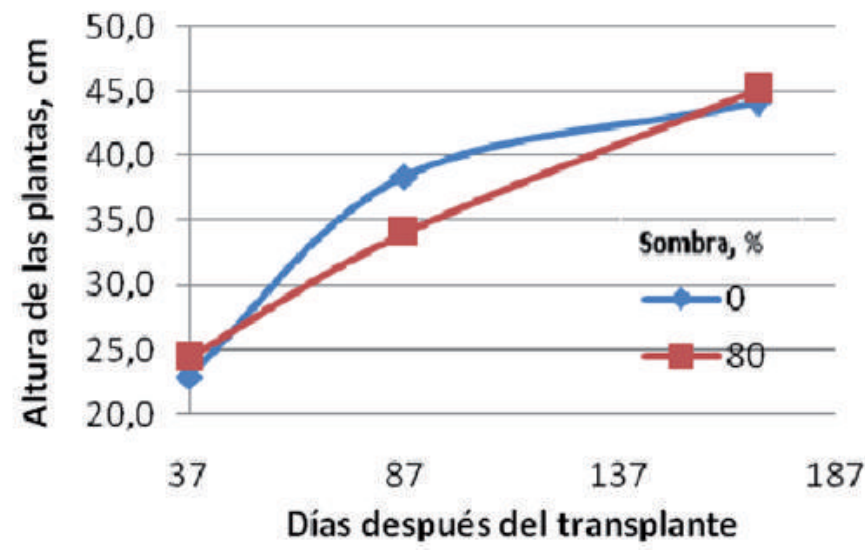

c. Sombra por DDT

Se observan diferencias altamente significativas para los días después del transplante de la variable altura de planta (Anexo 2). La prueba de significación de Tukey $5 \%$ muestra tres rangos de significación (Anexo 2). Para las interacciones entre: sombra, distancia de siembra y días después del transplante las diferencias son no significativas.

La distancia de siembray la sombra no influye significativamente en la a altura de la planta y producción de la col del monte sembrada por semilla en condiciones adversas.

La distancia de siembra influye significativamente en la producción de hojas para la col del monte sembrada por semilla.

En general la altura de planta presenta una interacción muy baja con la sombra. Estas plantas fueron atacadas por cochinillas lo que influyó en su desarrollo bajo sombra.

Número de hojas

Figura No 5

Interacciones de sombra, distancia y días después del transplante en la col del monte sembrada por semilla

a) Distancia de siembra, $\mathrm{cm}$

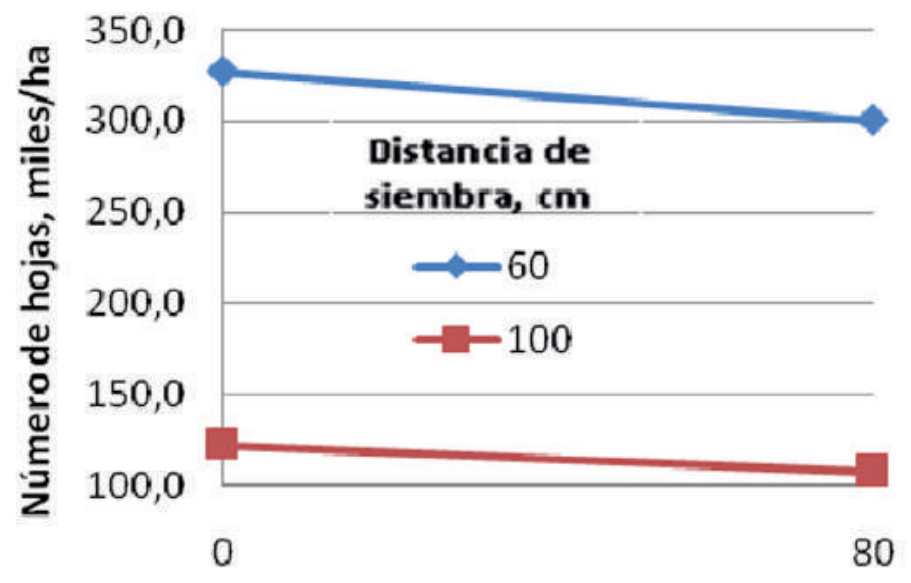

Sombra, \% 
b) Sombras por días después del trasplante.

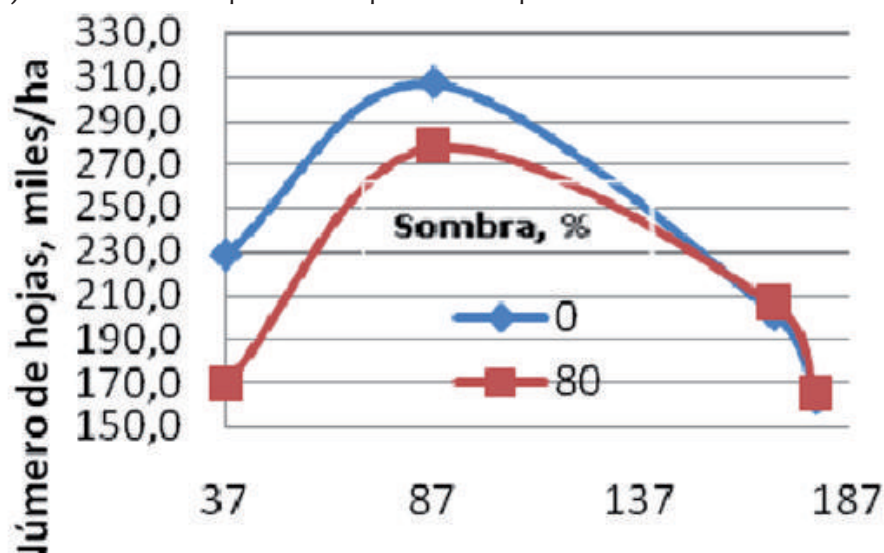

Días después del transplante

c) Distancias de siembra por días después del trasplante.

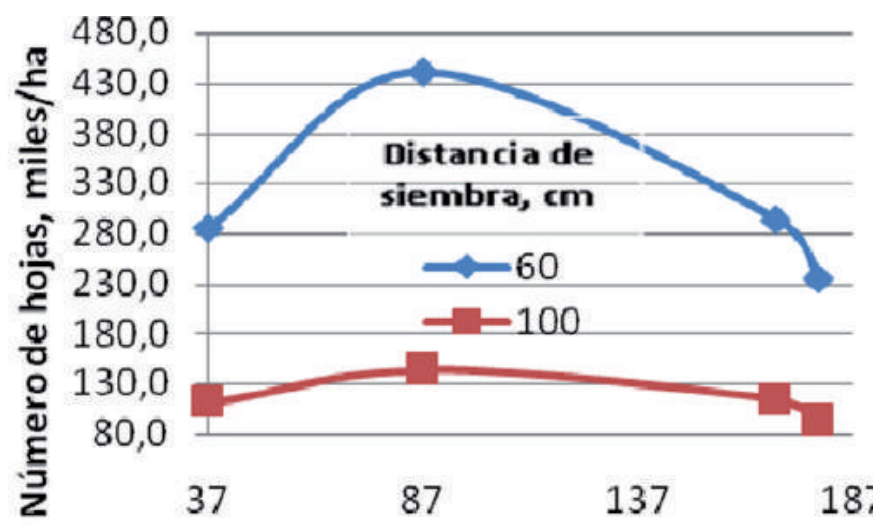

Días después del transplante

El número de hojas, presenta diferencias significativas en los días después del transplante y distancia de siembra (Anexo 2). Las interacciones y efectos principales de los demás factores muestran diferencias no significativas.

La prueba de significación de Tukey muestra 2 rangos de significación para los días después del transplante y distancia de siembra (Anexo 2)
Diámetro del tallo y cosecha de hojas (179 días después del transplante)

Figura N 6

Interacciones de sombra, distancia en la col del monte sembrada por semilla

a. Diámetro del tallo, $\mathrm{cm}$.

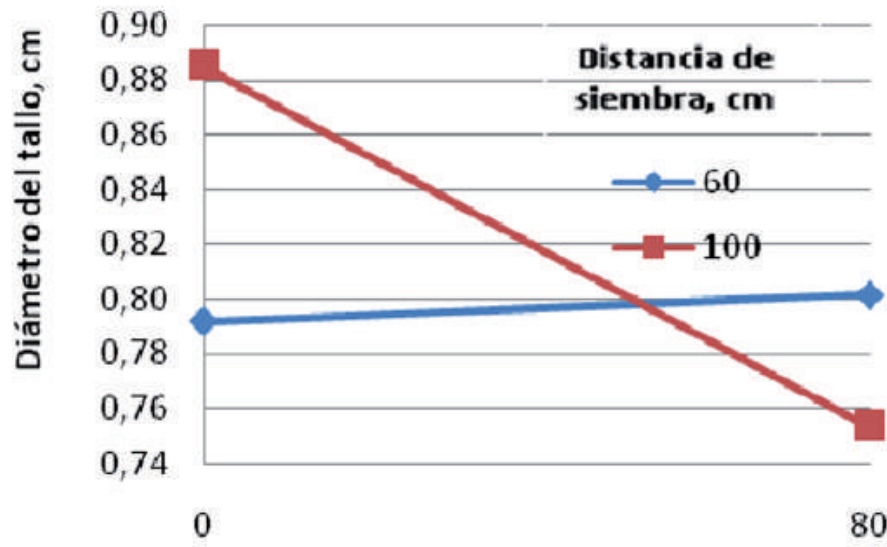

Sambra, \%

b. Cosecha de hojas, $\mathrm{kg} / \mathrm{ha}$.

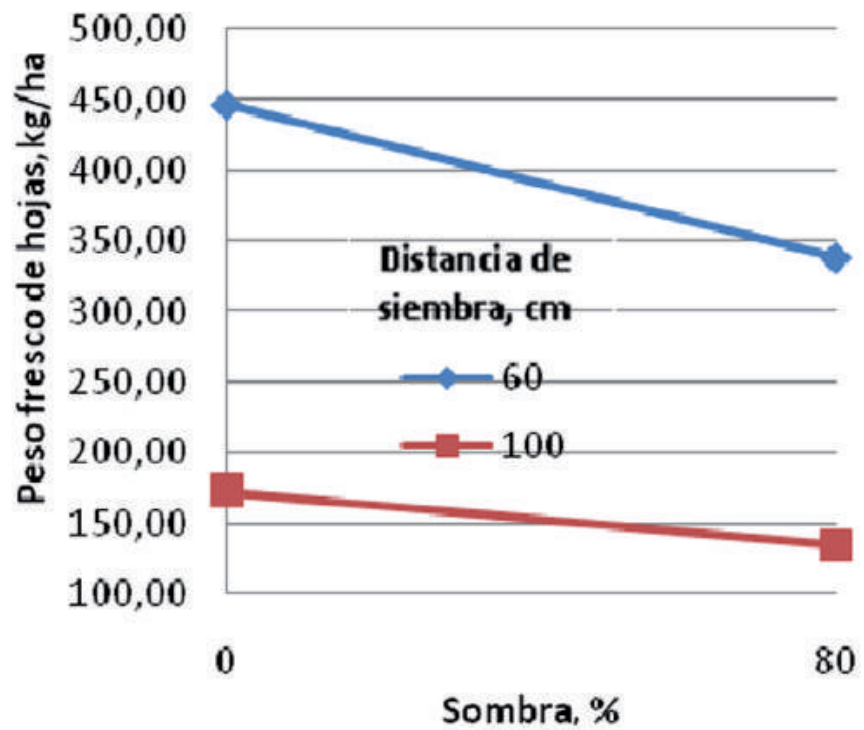

Se observan diferencias no significativas para el diámetro de tallo y cosecha de hojas al sembrar a diferentes distancias y sombra (Anexo 2) 
El peso fresco es numéricamente mayor cuando se siembra a $60 \mathrm{~cm}$ de distancia que a $100 \mathrm{~cm}$ (Figura No 6)

\section{Estacas}

Fenología

Figura No 7

Fenología de la col del monte sembrada por estacas

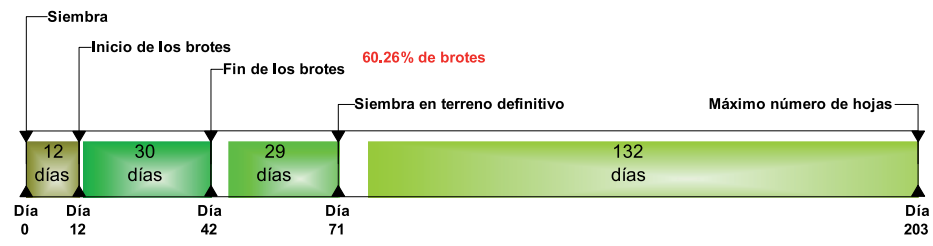

Cultivo

Altura de la planta

Figura No 8

Interacciones de sombra, distancia y días después del transplante en la col del monte sembrada por estacas

a. Días después del transplante por sombra

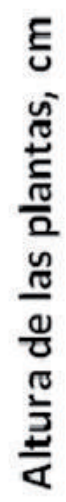

b. Distancia de siembra por sombra

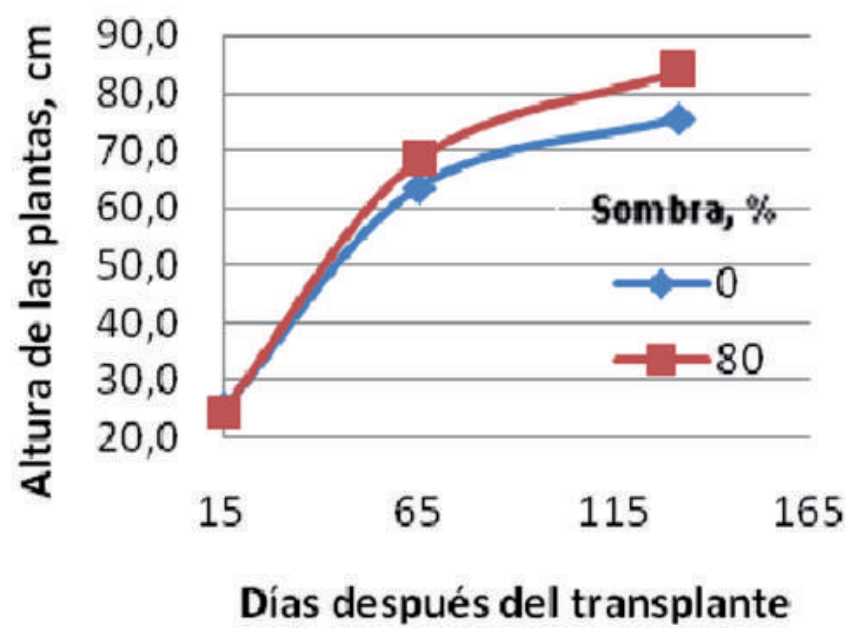

c. Días después del transplante por distancia de siembra

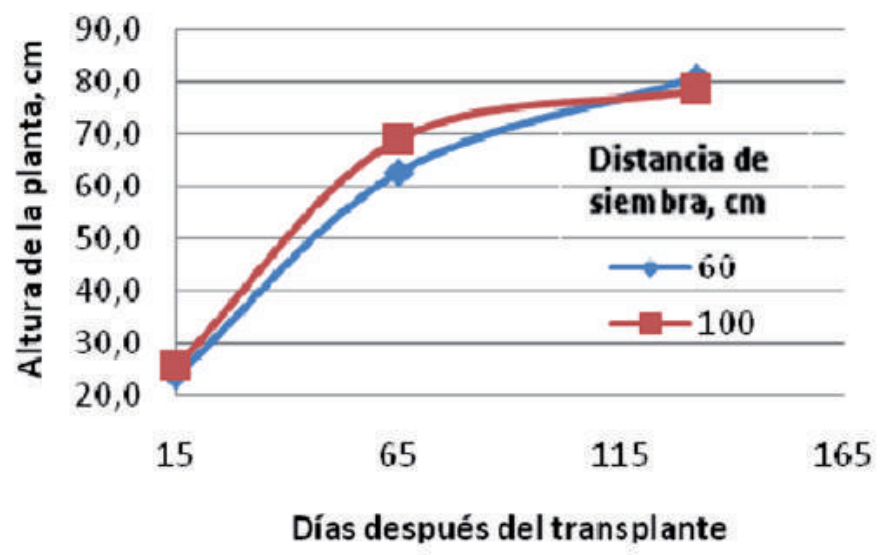

No se hizo análisis de varianza debido a que los grados de libertad para el error fueron 2. Las medias se observan en el Anexo 2.

Sombra, \% 


\section{Número de hojas}

Figura No 9

Interacciones de sombra, distancia y días después del transplante en la col del monte sembrada por estacas

a) Días después del transplante por sombra

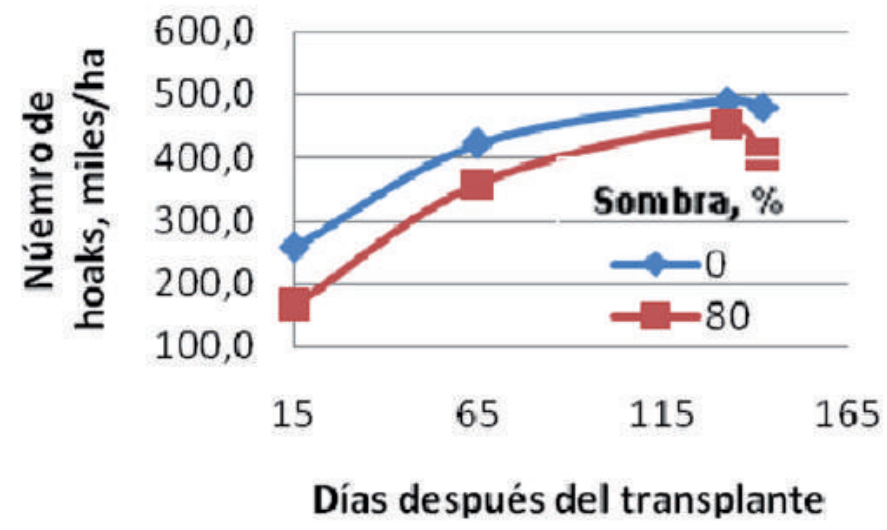

b) Días después del transplante por distancia de siembra
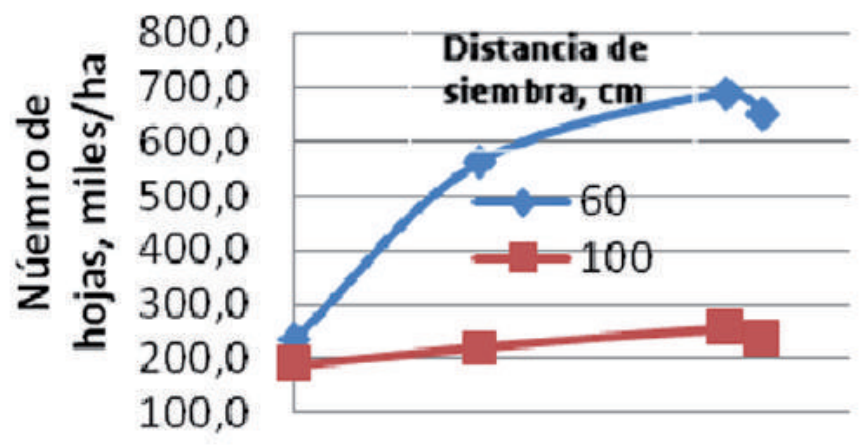

15

65

115

165

Días después del transplante

c)

Distancia de siembra por sombra

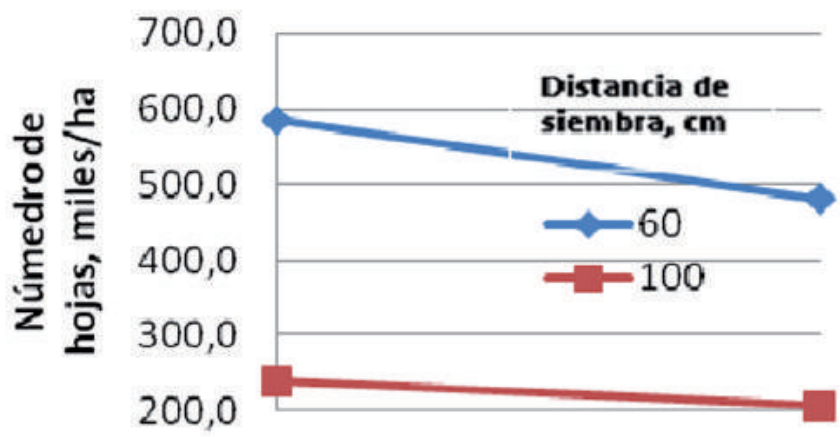

0
Se observan diferencias altamente significativas para días después del transplante, distancia de siembra por días después del transplante y distancia de siembra por días después del transplante por sombra. (Anexo 2)

La prueba de significación de Tukey muestra dos rangos de significación para los días después el transplante y distancia de siembra por días después del transplante y cinco rangos de significación para distancia de siembra por días después del transplante por sombra (Anexo 2)

Diámetro del tallo y cosecha de hojas (142 días después del transplante)

Figura No 10

Interacciones de sombra, distancia en la col del monte sembrada por estacas

a) Diámetro del tallo, $\mathrm{cm}$

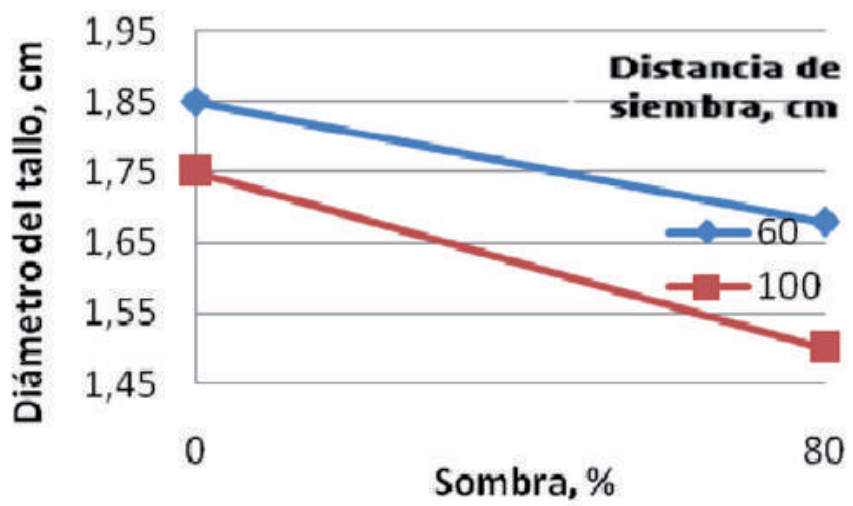

Sombra, \% 
b) Cosecha de hojas, $\mathrm{kg} / \mathrm{ha}$

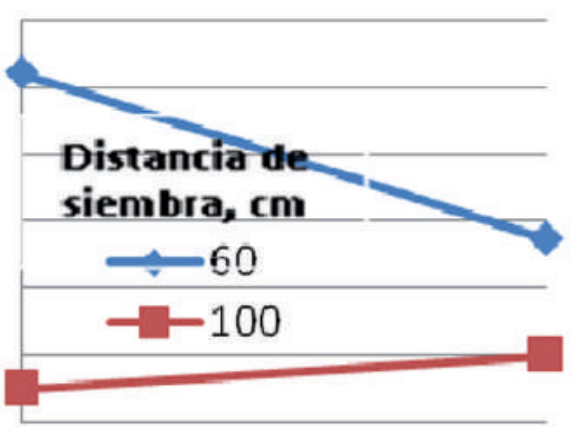

a Sombra, $\%$

Para estas variables no se hicieron análisis de varianzas, debido a que hay dos grados de libertad del error. Las medias están en el Anexo 2

Para las coles del monte sembradas por estacas, la altura tiende a ser mayor cuando se siembra con sombra. En general las plantas sembradas por estacas, al ser sembradas bajo sombra producen menos hojas que al ser sembradas a plena exposición solar.

Análisis bromatológico de la col de monte

\begin{tabular}{|c|c|c|c|c|c|c|}
\hline Identificación & Humedad & Ceniza & Grasa & Proteína & Fibra & ELNN \\
\hline Hojas secas & 0,00 & 12,50 & 7,8 & 25,7 & 13,5 & 40,50 \\
\hline Hojas frescas & 79,10 & 2,61 & 1,63 & 5,37 & 2,82 & 8,46 \\
\hline
\end{tabular}

ELNN Elementos no nitrogenados

Namau

Fenología

Figura No 11

Fenología del Namau

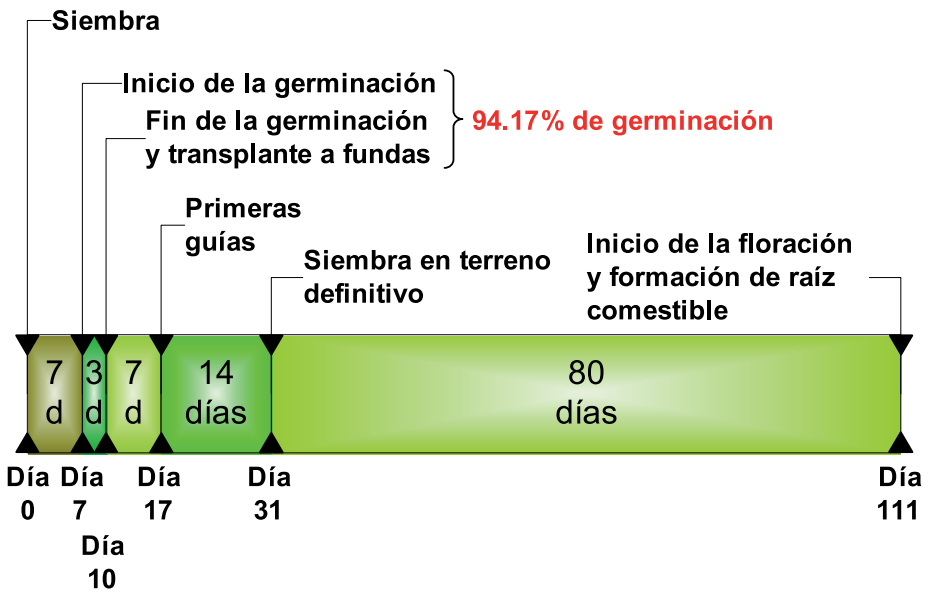

El porcentaje de germinación del Namau es del $94.17 \%$. Comienza a los 7 días. La raíz es susceptible al ataque de nemátodos, de tal forma que no se logró conseguir producción.

Análisis bromatológico del Namau

\begin{tabular}{|l|c|c|c|c|c|c|}
\hline Identificación & Humedad & Ceniza & Grasa & Proteína & Fibra & ELNN \\
\hline Tubérculo seco & 0,00 & 4 & 5,1 & 7,53 & 8,6 & 74,77 \\
\hline Tubérculo fresco & 72,30 & 1,11 & 1,41 & 2,09 & 2,38 & 20,71 \\
\hline
\end{tabular}

ELNN Elementos no nitrogenados

Sambo

Figura No 12

Fenología del Sambo

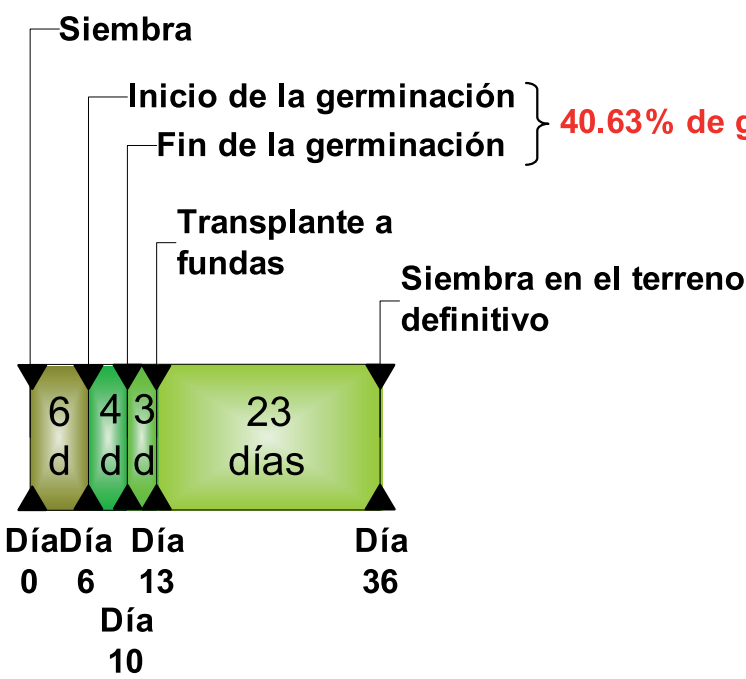


El sambo tiene $40.63 \%$ de germinación. Esta planta es muy susceptible

al ataque de malezas.

Zapallo

Figura No 13

Fenología del zapallo

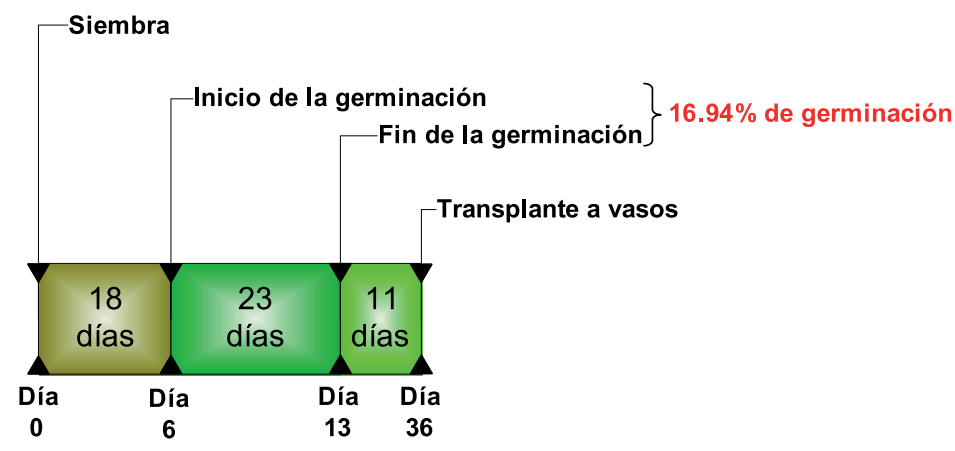

El zapallo tiene $16.94 \%$ de germinación. Esta especie nunca creció lo suficiente para poderla sembrar en el terreno definitivo.

\section{Labores culturales e incidencia de plagas y enfermedades}

Las labores culturales que se determinaron en esta zona para la col de monte y el cilantro de pozo son de simple deshierba por cuatro veces en el ciclo de cultivo a excepción del Namau y las cucurbitáceas que necesitaron a mas de las deshierba un sistema de tutoreo.

En lo referente a plagas y enfermedades, los resultados muestran que de las hortalizas cultivadas, la col de monte presento daños severos causados por la presencia de cochinilla (Dysmicoccus brevipes), causando inicialmente el marchitamiento de las plantas y luego la muerte debido a la destrucción del sistema radicular; sin embargo mostraron mayor resistencia aquellas que se propagaron por medio de estacas.

\section{Foto 1. Amarillamiento de la planta}

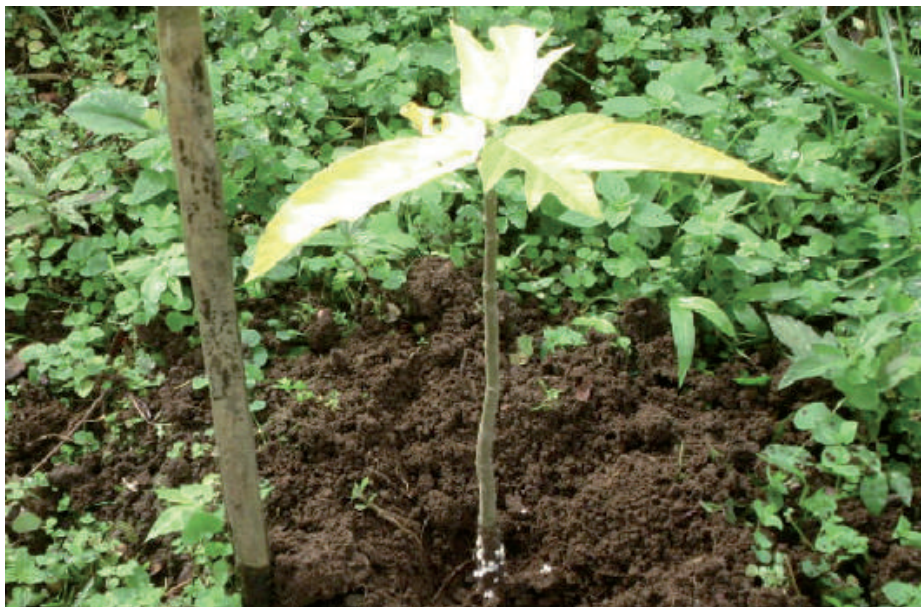

Foto 2. Ataque de cochinillas en raíces

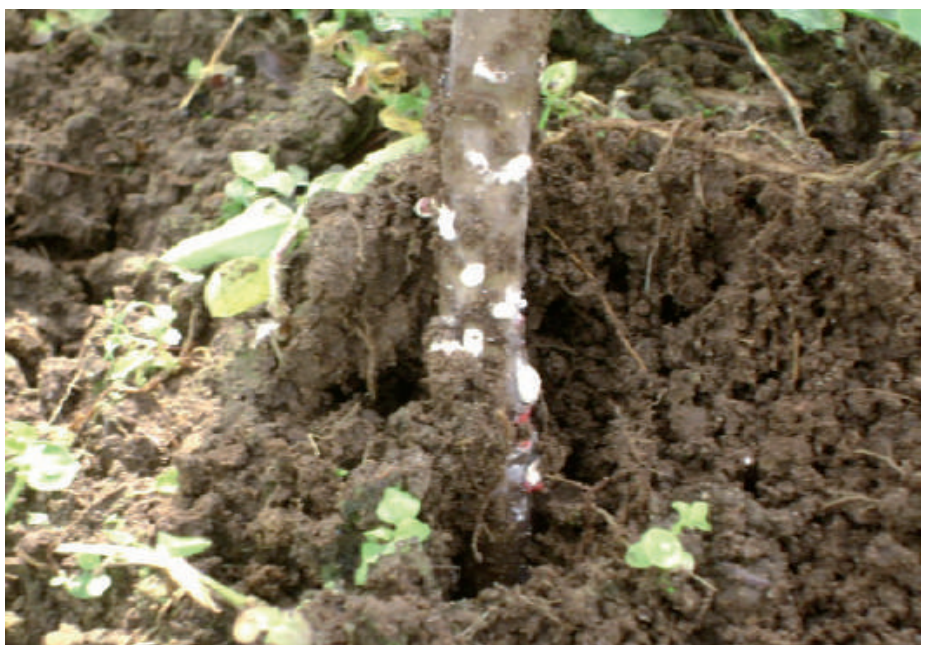

Namao

Los resultados mostraron la presencia moderada de insectos defoliadores que no causaron daño de consideración en las plantas; pero lo que si se observó fue un daño severo en raíces, causado por la presencia de cochinillas y nemátodos que no permitieron el desarrollo completo de la raíz, que en esta especie es la parte comestible.

\section{Tsafiqui=}


Foto 3 .
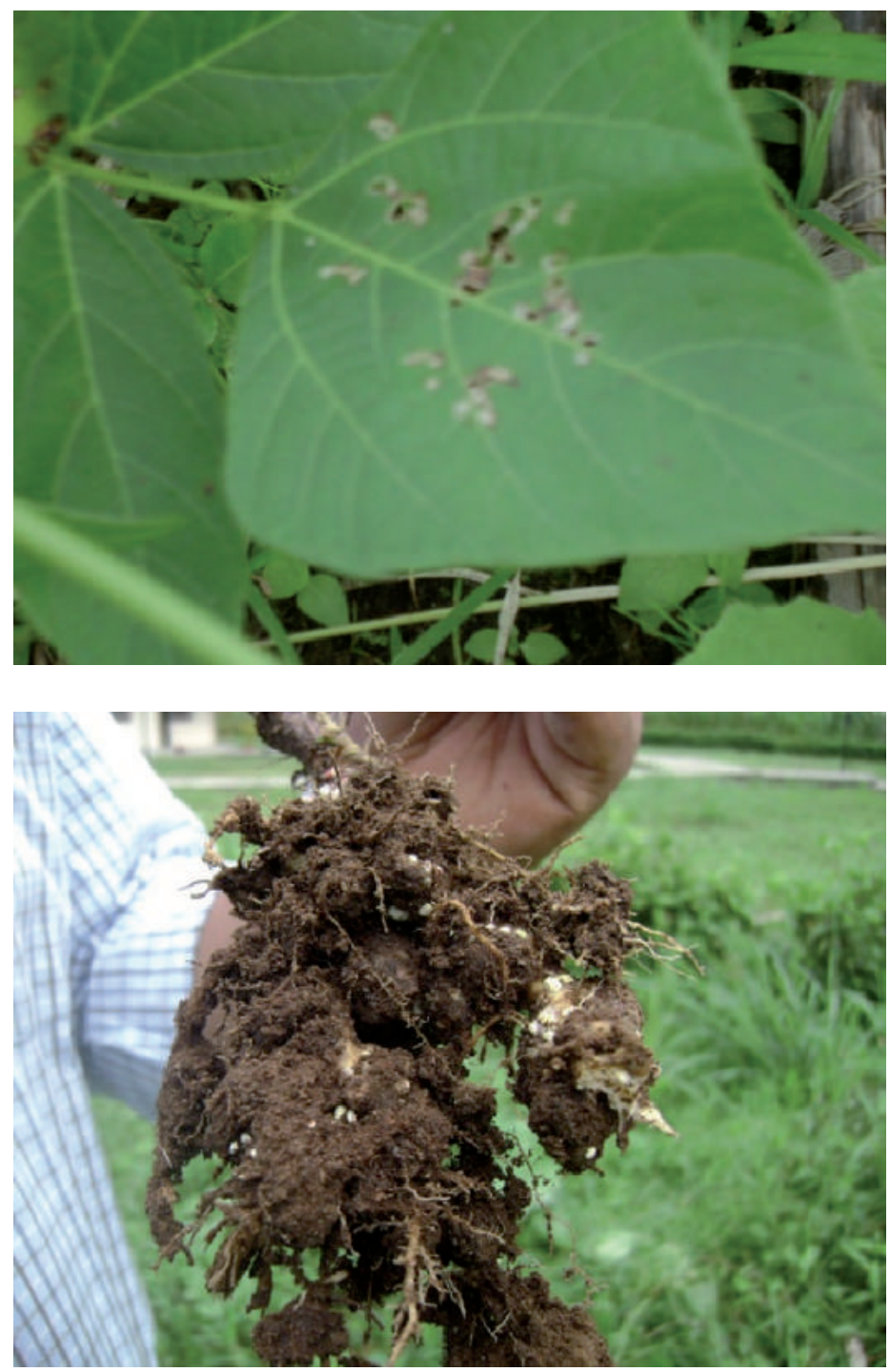

\section{Zapallo de montaña}

Los resultados mostraron una leve incidencia del minador de hojas

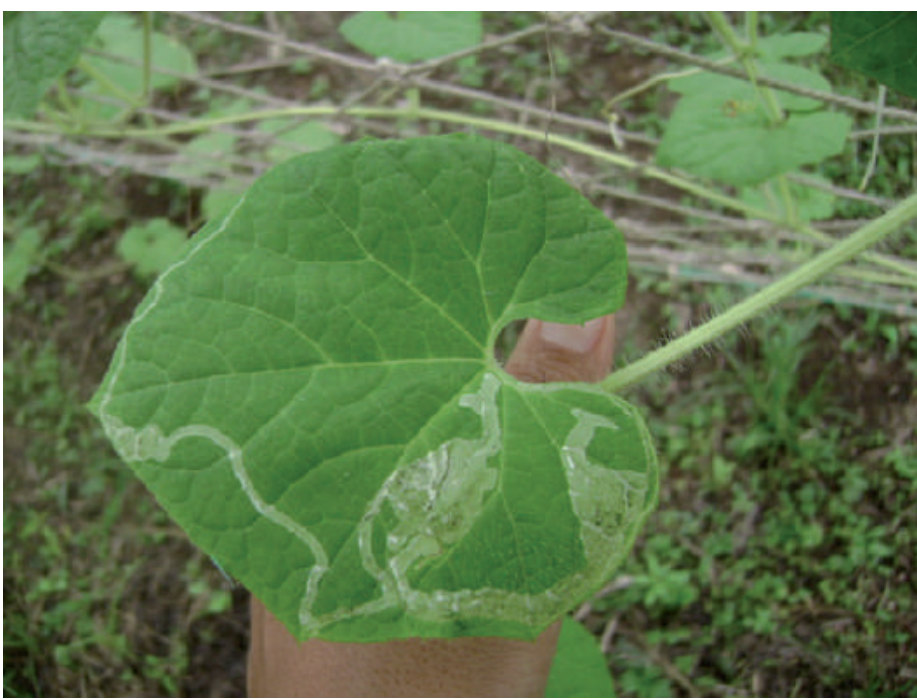

Daño causado por Lyriomiza sativa

\section{Conclusiones y Recomendaciones}

\section{Conclusiones}

- Se encontró cinco especies hortícolas nativas del trópico húmedo una de estas en la zona oriental del Ecuador no descartando la posibilidad de la existencia de más especies que por tiempo no se cubrió más lugares con estas condiciones climáticas, en dichas especies se caracterizó sus órganos vegetales de acuerdo a la botánica.

- Se estableció el ciclo de cultivo para las siguientes especies hortícolas Col del monte, Culantro de pozo y Namau; en el caso del Sambo y Zapallo por condiciones agrícolas adversas para 
estos cultivos no se pudo establecer el ciclo, pues estas plantas presentaron demasiada susceptibilidad al monocultivo siendo muy susceptibles a la competencia por malezas en el caso del sambo y en el caso del zapallo su resistencia a la vida en vivero y campo abierto.

- En el caso de las labores preculturales, no presentan ninguna alteración o cambio de las labores que necesitan los cultivos tradicionales, para el caso de las labores culturales se aplicaron deshierbas en un promedio de cuatro por ciclo, las mismas que van a variar o cambiar de acuerdo a las estaciones climáticas en la que se desarrolla el cultivo, para el caso de las cucurbitáceas y Namau fue necesario el tutoreo por el tipo de tallo rastrero y trepador que tienen, se presentó un caso singular al evaluar el cultivo de la col del monte bajo la incidencia de sombra presentando un mayor desarrollo y por consiguiente una mayor producción en presencia de esta. En las labores culturales, se observan diferencias no significativas para las distancias de siembra del Culantro de pozo en la producción de hojas. La distancia de siembra influye significativamente en la producción de hojas de la col sembrada por semilla. En la Col del monte sembrada por semilla la interacción distancia de siembra por sombra es altamente significativa.

- Por tratarse de especies nativas no presentan mayor ataque o incidencia de plagas y enfermedades, las que fueron afectadas en el ensayo como el caso de la cochinilla en la col del monte más atiende a la infestación que se encontraba en el suelo, no desmereciendo la susceptibilidad de esta especie al problema. El Namau fue susceptible de manera drástica al ataque de nemátodos, situación que no se observa en su lugar de origen (Macas).

\section{Recomendaciones}

- Debido a la abundancia de semillas que produce el Culantro y a que las distancias de siembra probadas no influyen en la producción de hojas, se puede investigar la siembra directa al voleo en el terreno definitivo.

- Controlar las cochinillas en el cultivo de Col del monte y probar distanciamientos de siembra con porcentajes de sombra, para determinar con mayor confiabilidad los efectos de los mismos en la producción de hojas.

- Investigar la siembra directa del Namau por su alta capacidad de germinación y el control de nematodos.

- Investigar el control de malezas en Sambo y Zapallo.

- Identificar más especies hortícolas aparte de las encontradas. 
- Puntualizar investigaciones específicas en los capos de nutrición, podas de las especies encontradas.

- Identificar potenciales usos agroindustriales y posibles mercados para estos productos.

\section{Bibliografía consultada}

- Alsina, L. 1980. Horticultura especial. 2 ed. Barcelona, Es. Síntesis. 272p.

- Alvarado, Y. 1999. El cultivo de culantro coyote (Eringyum foetidium L., APICEAE) Para Exportación. San José, Cr. 23p

- Becerra, N. 2002. Anatomía y morfología de los órganos vegetativos de las platas Vasculares. Bogota Co. Uniliblos. $275 p$

- ECUADOR. PRODUCTOS DE EXPORTACION NO TRADICIONALES. 1992. Quito, Ec. 73p.

- HOLDRIDGE. 1978. Mapa bioclimático. s/f.

- MINISTERIO DEAGRICULTURA YGANADERIA. 1986. Inventario de plagas,

- Enfermedades y malezas del Ecuador. MINISTERIO DE AGRICULTURA Y

- GANADERIA- COOPERACIÓN TÉCNICA ALEMANA. Quito.

- Parsons, D. 2007. Cucurbitáceas. México, Mx. Editorial: Trillas. $69 \mathrm{p}$.

- Terranova. 2000. Producción Agrícola I. Bogotá, Colombia. Segunda Ed. 284p
- Turchi, A. 1990. Guía practica de horticultura. Barcelona, España. CEAC. 236p.

\section{El Investigador}

\section{Xavier López Mejía \\ xlopez@ute.edu.ec}

Ingeniero Agrónomo; Universidad

Técnica de Ambato, 1999

Maestría en Agricultura Sostenible, Universidad Técnica de Ambato, 2008 


\section{Anexos}

Análisis de varianza

\section{Cullantro}

\begin{tabular}{|l|c|}
\hline \multicolumn{1}{|c|}{ Variable } & CV, \% \\
\hline Número de hojas, miles/ha (raíz cuadrada) & 5.52 \\
\hline Largo hoja mayor, cm & 17.71 \\
\hline
\end{tabular}

\begin{tabular}{|l|r|c|c|}
\hline \multicolumn{2}{|c|}{ Adeva } & \multicolumn{2}{c|}{ p-valor } \\
\hline \multicolumn{1}{|c|}{ F.V. } & gl & $\begin{array}{c}\text { Número } \\
\text { de hojas }\end{array}$ & $\begin{array}{c}\text { Largo de } \\
\text { hoja mayor }\end{array}$ \\
\hline Distancia de siembra & 2 & 0.1184 & 0.6932 \\
\hline Repeticiones & 5 & 0.5917 & 0.8299 \\
\hline Error Total & 10 & & \\
\hline \multicolumn{2}{|r|}{17} & & \\
\hline
\end{tabular}

\begin{tabular}{|c|c|c|}
\hline \multicolumn{3}{|c|}{ Medias } \\
\hline $\begin{array}{l}\text { Distancia de } \\
\text { siembra, cm }\end{array}$ & $\begin{array}{l}\text { Número de } \\
\text { hojas, miles/ha }\end{array}$ & $\begin{array}{l}\text { Largo de la hoja } \\
\text { más grande, cm }\end{array}$ \\
\hline 30 & 245.92 & 10.9 \\
\hline 40 & 212.06 & 11.9 \\
\hline 50 & 228.10 & 11.3 \\
\hline
\end{tabular}

Semilla

Altura

\section{Coll de monte}

\begin{tabular}{|c|c|}
\hline Variable & $\mathrm{CV}, \%$ \\
\hline Altura, cm & 16.18 \\
\hline
\end{tabular}

\begin{tabular}{|l|r|r|}
\hline \multicolumn{1}{|c|}{ F.V. } & \multicolumn{1}{c|}{ gl } & p-valor \\
\hline Repeticiones & 5 & 0.6664 \\
\hline Sombra & 1 & 0.7730 \\
\hline Error a & 5 & \\
\hline Dist. siembra & 1 & 0.7198 \\
\hline Sombra*Dist. siembra & 1 & 0.3856 \\
\hline Error b & 10 & \\
\hline DDT & 2 & $<0.0001$ \\
\hline Sombra*DDT & 2 & 0.1410 \\
\hline Dist. siembra*DDT & 2 & 0.9639 \\
\hline Dist. siembra*Sombra*DDT & 2 & 0.7840 \\
\hline Error c Total & 40 & \\
\hline \multicolumn{2}{|r|}{} \\
\hline
\end{tabular}

\section{Medias}

Altura de la planta, $\mathrm{cm}$

\begin{tabular}{|c|c|c|c|c|c|c|c|}
\hline & \multicolumn{6}{|c|}{ Sombra, \% } & \\
\hline \multirow{3}{*}{$\begin{array}{c}\text { Distancia } \\
\text { de } \\
\text { siembra, } \\
\mathrm{cm}\end{array}$} & \multicolumn{3}{|c|}{0} & \multicolumn{3}{|c|}{80} & \multirow[b]{3}{*}{ Media } \\
\hline & \multicolumn{6}{|c|}{ Días después del transplante (DDT) } & \\
\hline & 37 & 87 & 169 & 37 & 87 & 169 & \\
\hline 60 & 22.0 & 38.5 & 44.0 & 25.7 & 34.5 & 46.9 & 35.0 \\
\hline 100 & 23.8 & 38.3 & 44.3 & 23.2 & 33.7 & 43.3 & 33.9 \\
\hline Media DDT & 23.7A & $36.3 B$ & $44.7 C$ & 23.7A & 36.3B & $44.7 \mathrm{C}$ & \\
\hline $\begin{array}{c}\text { Media } \\
\text { sombra }\end{array}$ & & 34.3 & & & 34.5 & & \\
\hline
\end{tabular}

Letras distintas indican diferencias significativas. Tukey $p<=0.05$

\begin{tabular}{|c|c|c|c|}
\hline \multirow{2}{*}{$\begin{array}{c}\text { Distancia de } \\
\text { siembra, } \mathbf{c m}\end{array}$} & \multicolumn{3}{|c|}{ Días después del transplante } \\
\cline { 2 - 4 } & 37 & 87 & 169 \\
\hline 60 & 23.8 & 36.5 & 45.6 \\
\hline 100 & 23.5 & 36.0 & 43.7 \\
\hline
\end{tabular}

\begin{tabular}{|c|c|c|c|}
\hline \multirow{2}{*}{ Sombra, \% } & \multicolumn{3}{|c|}{ Días después del transplante } \\
\cline { 2 - 4 } & $\mathbf{3 7}$ & $\mathbf{8 7}$ & $\mathbf{1 6 9}$ \\
\hline 0 & 22.9 & 38.4 & 44.1 \\
\hline 80 & 24.4 & 34.1 & 45.1 \\
\hline
\end{tabular}


Hojas

\begin{tabular}{|c|c|}
\hline Variable & CV, \% \\
\hline Hojas, miles/ha (Raíz cuadrada) & 26.18 \\
\hline
\end{tabular}

\begin{tabular}{|c|c|c|}
\hline F.V. & gl & $\mathrm{p}$-valor \\
\hline Repeticiones & 5 & 0.8614 \\
\hline Sombra & 1 & 0.7267 \\
\hline Error a & 5 & \\
\hline Dist. siembra & 1 & 0.0001 \\
\hline Sombra*Dist. siembra & 1 & 0.7472 \\
\hline Error $b$ & 10 & \\
\hline DDT & 3 & 0.0004 \\
\hline Sombra*DDT & 3 & 0.4325 \\
\hline Dist. siembra*DDT & 3 & 0.3179 \\
\hline Dist. siembra*Sombra*DDT & 3 & 0.3524 \\
\hline Error c & 60 & \\
\hline Total & 95 & \\
\hline
\end{tabular}

Medias

\begin{tabular}{|c|c|c|c|c|c|c|c|c|c|}
\hline & \multicolumn{7}{|c|}{ Sombra, \% } & \\
\hline & \multicolumn{7}{|c|}{0} & \multicolumn{7}{|c|}{80} & \\
\hline \multirow{2}{*}{$\begin{array}{c}\text { Distancia de } \\
\text { siembra, } \mathrm{cm}\end{array}$} & 37 & 87 & 169 & 179 & 37 & 87 & 169 & 179 & Media \\
\hline 60 & 336.8 & 459.8 & 283.3 & 229.9 & 235.2 & 422.3 & 304.7 & 240.6 & $314.1 \mathrm{~A}$ \\
\hline 100 & 119.3 & 154.0 & 119.3 & 96.2 & 102.0 & 132.8 & 107.8 & 88.5 & $118.8 \mathrm{~B}$ \\
\hline Media DDT & $198.3 \mathrm{~B}$ & $\mathbf{2 9 2 . 2 \mathrm { A }}$ & $203.8 \mathrm{~B}$ & $163.8 \mathrm{~B}$ & $198.3 \mathrm{~B}$ & $292.2 \mathrm{~A}$ & $203.8 \mathrm{~B}$ & $163.8 \mathrm{~A}$ & \\
\hline Media sombra & \multicolumn{8}{|c|}{224.8} & \multicolumn{7}{|c|}{204.2} & \\
\hline
\end{tabular}

Letras distintas indican diferencias significativas. Tukey $p<=0.05$.

Transformación a raíz cuadrada

\begin{tabular}{|c|c|c|c|c|}
\hline \multirow{2}{*}{$\begin{array}{l}\text { Distancia de } \\
\text { siembra, cm }\end{array}$} & \multicolumn{4}{|c|}{ Días después del transplante } \\
\cline { 2 - 5 } & 37 & 87 & 169 & 179 \\
\hline 60 & 286.0 & 441.0 & 294.0 & 235.2 \\
\hline 100 & 110.7 & 143.4 & 113.5 & 92.4 \\
\hline
\end{tabular}

\begin{tabular}{|c|c|c|c|c|}
\hline \multirow{2}{*}{ Sombra, \% } & \multicolumn{4}{|c|}{ Días después del transplante } \\
\cline { 2 - 5 } & 37 & 87 & 169 & 179 \\
\hline 0 & 228.1 & 306.9 & 201.3 & 163.1 \\
\hline 80 & 168.6 & 277.6 & 206.2 & 164.5 \\
\hline
\end{tabular}

\begin{tabular}{|c|c|c|}
\hline Distancia de & \multicolumn{2}{|c|}{ Sombra, \% } \\
\cline { 2 - 3 } siembra, cm & 0 & 80 \\
\hline 60 & 327.4 & 300.7 \\
\hline 100 & 122.2 & 107.8 \\
\hline
\end{tabular}

Diámetro del tallo y cosecha de hojas

\begin{tabular}{|l|c|}
\hline \multicolumn{1}{|c|}{ Variable } & $\mathrm{CV}, \%$ \\
\hline Diámetro, cm & 20.87 \\
\hline Cosecha, kg/ha (Logaritmo base 10) & 23.82 \\
\hline
\end{tabular}

\begin{tabular}{|c|c|c|c|}
\hline & & \multicolumn{2}{|c|}{ p-valor } \\
\hline F.V. & gl & Diámetro & Cosecha \\
\hline Repeticiones & 5 & 0.9695 & 0.5978 \\
\hline Sombra & 1 & 0.6652 & 0.9110 \\
\hline Error a & 5 & & \\
\hline Distancia de siembra & 1 & 0.7505 & 0.1438 \\
\hline Distancia de siembra*Sombra & 1 & 0.3276 & 0.4310 \\
\hline Error b & 10 & & \\
\hline Total & 23 & & \\
\hline
\end{tabular}

Medias

\begin{tabular}{|c|c|c|r|}
\hline \multirow{2}{*}{$\begin{array}{l}\text { Distancia de } \\
\text { siembra, cm }\end{array}$} & \multicolumn{2}{|c|}{ Sombra, \% } & \multicolumn{1}{|c|}{} \\
\cline { 2 - 3 } & 0 & 80 & Media \\
\hline 60 & 446.60 & 338.13 & 392.37 \\
\hline 100 & 172.54 & 134.20 & 153.37 \\
\hline Media & 309.57 & 236.17 & \multicolumn{2}{|c}{} \\
\hline
\end{tabular}

a) Cosecha

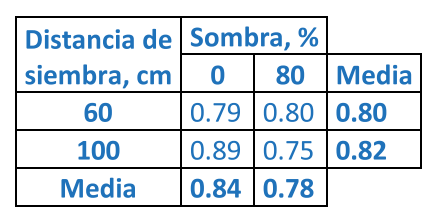

b) Diámetro

\section{Estacas}

Medias

Altura, cm

\begin{tabular}{|c|c|c|c|c|c|c|c|}
\hline & \multicolumn{5}{|c|}{ Sombra, \% } & \\
\hline & \multicolumn{5}{|c|}{0} & \multicolumn{3}{c|}{80} & \\
\hline \multirow{2}{*}{$\begin{array}{c}\text { Distancia de } \\
\text { siembra, cm }\end{array}$} & 15 & 65 & 132 & 15 & 65 & 132 & Media \\
\hline \multirow{2}{*}{ Días después del transplante DDT } & 25.0 & 64.0 & 81.5 & 23.0 & 61.5 & 80.5 & 55.9 \\
\hline 100 & 25.0 & 63.0 & 69.5 & 26.0 & 75.0 & 87.5 & 57.7 \\
\hline Media DDT & 24.8 & 65.9 & 79.8 & 24.8 & 65.9 & 79.8 & \\
\hline Media sombra & 54.7 & \multicolumn{5}{c|}{58.9} & \\
\hline
\end{tabular}




\begin{tabular}{|c|c|c|c|}
\hline \multirow{2}{*}{ Sombra, \% } & \multicolumn{3}{|c|}{ Días después del transplante } \\
\cline { 2 - 4 } & 15 & 65 & 132 \\
\hline $\mathbf{0}$ & 25.0 & 63.5 & 75.5 \\
\hline $\mathbf{8 0}$ & 24.5 & 68.3 & 84.0 \\
\hline
\end{tabular}

\begin{tabular}{|c|c|c|c|}
\hline \multirow{2}{*}{$\begin{array}{c}\text { Distancia de } \\
\text { siembra, cm }\end{array}$} & \multicolumn{3}{|c|}{ Días después del transplante } \\
\cline { 2 - 4 } & 15 & 65 & 132 \\
\hline 60 & 24.0 & 62.8 & 81.0 \\
\hline 100 & 25.5 & 69.0 & 78.5 \\
\hline
\end{tabular}

\begin{tabular}{|c|c|c|}
\hline Distancia de & \multicolumn{2}{|c|}{ Sombra, $\%$} \\
\cline { 2 - 3 } siembra, $\mathrm{cm}$ & 0 & 80 \\
\hline 60 & 56.8 & 55.0 \\
\hline 100 & 52.5 & 62.8 \\
\hline
\end{tabular}

Hojas, miles/ha

\begin{tabular}{|c|c|}
\hline Variable & CV, \% \\
\hline Hojas, conteo (raíz cuadrada) & 8.00 \\
\hline
\end{tabular}

\begin{tabular}{|l|r|r|}
\hline \multicolumn{1}{|c|}{ F.V. } & \multicolumn{1}{c|}{ gl } & p-valor \\
\hline Repeticiones & 1 & 0.2825 \\
\hline Sombra & 1 & 0.1806 \\
\hline Error a & 1 & \\
\hline Dist. siembra & 1 & 0.0017 \\
\hline Sombra*Dist. siembra & 1 & 0.3959 \\
\hline Error b & 2 & \\
\hline DDT & 3 & $<0.0001$ \\
\hline Sombra*DDT & 3 & 0.2796 \\
\hline Dist. Siembra*DDT & 3 & $\mathbf{0 . 0 0 0 4}$ \\
\hline Dist. Siembra*Sombra*DDT & 3 & $\mathbf{0 . 0 0 2 7}$ \\
\hline Error c Total & 12 & \\
\hline \multicolumn{2}{|r|}{31} & \\
\hline
\end{tabular}

Letras distintas indican diferencias significativas. Tukey $\mathrm{p}<=0.05$ transformación a raíz cuadrada.

Número de hojas, miles/ha

\begin{tabular}{|c|c|c|c|c|c|c|c|c|c|}
\hline & \multicolumn{8}{|c|}{ Sombra, $\%$} & \\
\hline & \multicolumn{4}{|c|}{0} & \multicolumn{4}{|c|}{80} & \multirow[b]{3}{*}{ Media } \\
\hline \multirow{2}{*}{$\begin{array}{l}\text { Distancia de } \\
\text { siembra, cm }\end{array}$} & \multicolumn{8}{|c|}{ Días después del transplante DDT } & \\
\hline & 15 & 65 & 132 & 142 & 15 & 65 & 132 & 142 & \\
\hline 60 & $224.5 \mathrm{CD}$ & $625.5 \mathrm{~A}$ & 737.7A & $753.8 \mathrm{~A}$ & $240.6 \mathrm{CD}$ & $497.2 A B$ & $641.5 \mathrm{~A}$ & $545.3 \mathrm{~A}$ & 533.3 \\
\hline 100 & $288.7 \mathrm{BC}$ & $219.4 \mathrm{CD}$ & $242.5 \mathrm{CD}$ & $207.9 \mathrm{CD}$ & $86.6 \mathrm{D}$ & $219.4 \mathrm{CD}$ & $265.6 \mathrm{BC}$ & $259.8 \mathrm{BC}$ & 223.7 \\
\hline Media DDT & $210.1 \mathrm{~B}$ & $390.4 \mathrm{~A}$ & $471.8 \mathrm{~A}$ & 441.7A & 210.1B & $390.4 \mathrm{~A}$ & $471.8 \mathrm{~A}$ & $441.7 \mathrm{~A}$ & \\
\hline Media sombra & \multicolumn{4}{|c|}{412.5} & \multicolumn{4}{|c|}{344.5} & \\
\hline
\end{tabular}

Letras distintas indican diferencias significativas. Tukey $p<=0.05$. Transformación a raíz cuadrada

\begin{tabular}{|c|c|c|c|c|c|c|c|c|c|}
\hline \multirow{2}{*}{ Sombra, \% } & \multicolumn{4}{|c|}{ Días después del transplante } & \multirow{2}{*}{$\begin{array}{l}\text { Distancia de } \\
\text { siembra, cm }\end{array}$} & \multicolumn{4}{|c|}{ Días después del transplante } \\
\hline & 15 & 65 & 132 & 142 & & 15 & 65 & 132 & 142 \\
\hline 0 & 256.6 & 422.4 & 490.1 & 480.8 & \begin{tabular}{|l|}
60 \\
\end{tabular} & $232.6 \mathrm{~B}$ & $561.3 \mathrm{~A}$ & $689.6 \mathrm{~A}$ & $649.5 \mathrm{~A}$ \\
\hline 80 & 163.6 & 358.3 & 453.6 & 402.6 & 100 & 187.6B & $219.4 \mathrm{~B}$ & $254.0 \mathrm{~B}$ & 233.8B \\
\hline
\end{tabular}

\begin{tabular}{|c|c|c|}
\hline Distancia de & \multicolumn{2}{|c|}{ Sombra, \% } \\
\cline { 2 - 3 } siembra, cm & 0 & 80 \\
\hline 60 & 585.4 & 481.1 \\
\hline 100 & 239.6 & 207.9 \\
\hline
\end{tabular}

Medias de cosecha de hojas, $\mathrm{kg} / \mathrm{ha}$ y diámetro del tallo, $\mathrm{cm}$

\begin{tabular}{|c|c|c|l|}
\hline \multirow{2}{*}{$\begin{array}{c}\text { Distancia de } \\
\text { siembra, cm }\end{array}$} & \multicolumn{2}{|c|}{ Sombra, \% } & \multicolumn{1}{|c|}{} \\
\cline { 2 - 3 } & 0 & 80 & Media \\
\hline 60 & 6225.94 & 3752.89 & 4989.41 \\
\hline 100 & 1505.89 & 2006.93 & 1756.41 \\
\hline Media & 3865.92 & 2879.91 & \multicolumn{2}{|l}{} \\
\hline
\end{tabular}

a) Cosecha

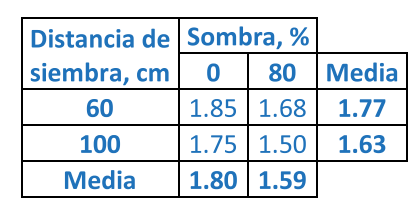

b) Diámetro 